\title{
Myt Transcription Factors prevent stress-response gene over-activation to enable postnatal pancreatic $\beta$ cell proliferation and function
}

Ruiying $\mathrm{Hu}^{1, a}$, Emily Walker2, a, Yanwen $\mathrm{Xu}^{1}$, a, Chen Huang1,3, a, Chen Weng4, Gillian E. Erickson ${ }^{1}$, Anastasia Golovin ${ }^{5}$, Xiaodun Yang1, Marcella Brissova5, Appakalai N. Balamurugan ${ }^{6}$, Christopher V. E. Wright ${ }^{1}$, Yan $\mathrm{Li}^{4}$, Roland Stein 3 , and Guoqiang Gu${ }^{1}$,\#

1, Vanderbilt Program in Developmental Biology, Department of Cell and Developmental Biology, and Center for Stem Cell Biology, Vanderbilt University School of Medicine, Nashville, TN 37232.

2, Department of Molecular Physiology and Biophysics, Vanderbilt University School of Medicine, Nashville, TN 37232.

3, Current address: Lester and Sue Smith Breast Center, Baylor College of Medicine, Houston, Texas 77030.

4, Department of Genetics and Genome Sciences, Case Western Reserve University, Cleveland, Ohio 44106.

5. Department of Medicine, Vanderbilt Medical Center, Nashville, TN27232.

6, Department of Surgery, Clinical Islet Transplantation Laboratory, Cardiovascular Innovation Institute, University of Louisville, Louisville, KY, 40202.

a. These authors contributed equally to the work.

*: Corresponding authors and lead contact:

Guoqiang Gu: guoqiang.gu@vanderbilt.edu 615-936-3634 


\section{Summary}

Although stress response maintains cell function and survival under adverse conditions, over-activation of late-stage stress-gene effectors causes dysfunction and death. Here we show that the Myelin Transcription Factors (Myt 1, 2, and 3 TFs) prevent this over-activation. Co-inactivating Myt TFs in mouse pancreatic progenitors compromised postnatal $\beta$-cell function, proliferation, and survival, preceded by upregulation of late-stage stress-response genes Activating Transcription Factors (e.g., Atf4) and Heat Shock Proteins (Hsps). Myt1 binds the putative enhancers of Atf4 and Hsps, whose over-expression in mouse $\beta$ cells largely recapitulated the Myt mutant phenotypes. Moreover, Myt(MYT)-TF levels were upregulated in functional mouse and human $\beta$ cells by metabolic stress but downregulated in those of type 2 diabetic islets that display ATF4 and HSP overactivation. Lastly, human MYT knockdown caused stress-gene over-activation and death in Endo- $\beta \mathrm{H} 1$ cells. These findings suggest that the Myt TFs restrict stressresponse to physiologically tolerable levels in mice and human.

\section{Introduction}

The unfolded-protein response (UPR) and oxidative stress response (OSR) are central protectors of cell function and survival (Juliana et al., 2017; Sies et al., 2017). Unfolded proteins in the endoplasmic reticulum (ER) sequester resident chaperones such as GRP78/Bip and stimulate early sensor-effectors of the stress response, including Inositol Requiring 1 (IRE1), Protein Kinase RNA-like Endoplasmic Reticulum Kinase (PERK), and Activating Transcription Factor 6 
(ATF6) (Cao and Kaufman, 2014). Their activation downregulates the overall protein translation but preferentially induces the production of several later-acting stress-pathway effectors such as Atf4, heat-shock proteins (Hsps), proteins required for endoplasmic-reticulum-associated protein degradation (ERAD) via splicing, transcription, translation, and/or post-translational mechanisms (Papa, 2012; Shen et al., 2002). These responses serve to facilitate nascent protein folding and to reduce the proportion of mis-folded proteins. Moreover, conditions causing cytoplasmic protein denaturation, such as heat shock and reactive-oxygen species (ROS), activate heat-shock factors (HSFs) that induce transcription of Hsp and chaperonin (Cct) genes (Fulda et al., 2010; Ostling et al., 2007). ROS also activates the Nrf2 transcription factor (TF) to induce the production of enzymes that remove toxic reactive-oxygen species (Sies et al., 2017). Collectively, these responses allow cells to survive in stressful environments. However, chronic and/or over-activation of the stress response causes cell dysfunction and death (Hotamisligil and Davis, 2016). For cells such as neuronal and pancreatic islet $\beta$ cells that cannot be readily regenerated, a substantial loss of cell numbers in this manner could permanently compromise organ function and cause neuronal diseases and type 2 diabetes (T2D) (Cao and Kaufman, 2014; Chaari, 2019).

Over a long lifespan, pancreatic $\beta$ cells make exceedingly large amounts of insulin, representing roughly $5-10 \%$ of the total protein pool, to sustain the ability for cyclical insulin secretion as the principal factor that maintains glucose homeostasis. This production level inevitably produces some mis-folded proinsulin, sometimes up to $20 \%$ of nascent proinsulin, in the ER - sufficiently high to induce 
UPR (Cao and Kaufman, 2014; Sun et al., 2015; Szabat et al., 2016). Increased mitochondrial glucose metabolism in $\beta$ cells is not only the main inducer for insulin secretion, but also increases ROS production. While low ROS levels promote insulin secretion, high levels activate OSR and UPR (Guo et al., 2013; Hartl et al., 2011). The UPR and OSR of active, healthy $\beta$ cells facilitates protein homeostasis and promotes proper insulin secretion and $\beta$-cell proliferation (Lipson et al., 2006; Sharma et al., 2015; Szabat et al., 2016). However, sustained high levels of stress signals attenuate general protein translation and contribute to $\beta$-cell dysfunction by activating $\mathrm{CHOP}$ and other pro-apoptotic genes (Iurlaro and Munoz-Pinedo, 2016). Consequently, $\beta$ cells are challenged to tune their stress response within a range that allows robust secretory function to be balanced with healthy cell survival (Fonseca et al., 2011; Song et al., 2008).

The Myelin Transcription Factors (Myt TFs) [i.e. Myt1 (Nzf2), Myt2 (Myt1L or Nzf1), and Myt3 (Nzf3 or St18)] are responsive to stress signals. For example, hyperglycemia and hyperlipidemia potentiate Myt3 expression in $\beta$ cells (Henry et al., 2014; Tennant et al., 2012), a response associated either with cell survival (Henry et al., 2014) or cell death (Tennant et al., 2016). This family of zinc-finger proteins is also expressed in neural and neuro-endocrine cells (Gu et al., 2004; Henry et al., 2014; Kim and Hudson, 1992; Tennant et al., 2012; Vasconcelos et al., 2016; Wang et al., 2007), wherein they regulate cell differentiation by repressing expression of non-neuronal genes (Vasconcelos et al., 2016). Precisely defining Myt1, 2 and/or 3 activities, however, has been greatly hampered by the genetic compensation between the members (Wang et al., 2007). 
Myt1, 2, and 3 were recently shown to be largely dispensable for $\beta$-cell differentiation (Liu et al., 2019). Yet they were found to repress Synaptotagmin 4 (Syt4) expression in neonatal islet $\beta$ cells, a key regulator of vesicle-plasma membrane fusion and insulin secretion in adult-stage $\beta$ cells (Huang et al., 2018). Normally, Syt4 levels increase during postnatal $\beta$-cell maturation and are required for mediating glucose-sensitive insulin release. Early embryonic removal of $M y t 1,2$, and 3 by expression of $P d x 1$-driven Cre in $M y t 1^{F / F} ; M y t 2^{F / F} ; M y t 3^{F / F}$ mice (termed $6 F$; $P d x 1^{\text {Cre }}$ hereafter) resulted in defective insulin secretion in post-weaning islets due, in part, to the precocious activation of Syt4 production. Yet overexpression of Syt4 in perinatal $\beta$ cells did not result in overt diabetes, thus leading to the conclusion that it alone cannot be responsible for all the effects observed in $6 F$; $P d x 1^{\text {Cre }}$ mice (Huang et al., 2018), and suggesting that other cellular processes must be dysregulated in the absence of Myt TFs. We show here their importance in controlling an appropriate level of activity of cellular stress pathways, which is very influential in maintaining normal $\beta$-cell function, proliferation, and survival.

\section{Results}

\section{Inactivation of $M y t$ genes compromised $\beta$-cell proliferation and survival}

To gain clues regarding the processes regulated by Myt TFs in $\beta$ cells, the physiological and cellular defects of $6 F$; Pdx1Cre (i.e., $M y t 1^{F / F} ; M y t 2^{F / F}$; $M y t 3^{F / F}$; $P d x 1^{C r e}$ ) mice were examined in greater detail. Myt proteins were efficiently inactivated in $6 F ; P d x 1^{\text {Cre }}$ pancreatic cells (Figure S1A1-A6). There was no change in Myt levels in the hypothalamus, where some spurious $P d x 1^{\text {Cre }}$ activity was reported 
(Figure S1B0-B8) (Schwartz et al., 2010). There were also no obvious defects in the exocrine pancreas of $6 F$; $P d x 1^{\text {Cre }}$ mice (Figure S1C1-C2), consistent with the endocrine-specific pattern of Myt TF production (Figure S1A1-A3).

$6 F$; $P d x 1^{C r e}$ mutant mice displayed a higher fasting blood-glucose level as early as postnatal day 14 (P14) in comparison to the wild-type, $P d x 1^{C r e}$, and $M y t 1^{F / F}$; $M y t 2^{F / F} ; M y t 3^{F / F}$ (termed $6 F$ ) controls, and this difference became more pronounced as the mice aged (Figure 1A, Table S1). This temporal pattern correlated with reductions in both $6 F ; P d x 1^{\text {Cre }}$ body weight (Figure $1 \mathrm{~A}$ ) and glucose-induced plasma insulin level (Figure 1B). There was no change in the plasma glucagon level (Figure 1C), an $\alpha$-cell-secreted hormone that induces gluconeogenesis in (for example) the liver, nor a detectably compromised insulin sensitivity (Figure 1D). Ruling out whole-body effects, GSIS was also compromised by P14 in isolated $6 F$; Pdx1 ${ }^{\text {Cre }}$ islets (Figure 1E).

Although $6 F ; P d x 1^{\text {Cre }}$ mutant islets appeared largely normal in newborn mice (Liu et al., 2019), they became smaller and displayed a much more aspherical morphology at later stages in relation to controls (Figure 1F, G). A reduction in $\beta$-cell mass was observed within two weeks of birth (Figure 1H), which accompanied both decreased proliferation (Figure 1I-K) and increased apoptotic cell death (Figure 1LQ). These findings suggest that the Myt TFs are required for postnatal $\beta$-cell function, proliferation, and survival.

\section{Myt factors are necessary for retaining hallmark features of mature $\beta$ cells}


Molecular defects in perinatal $6 F ; P d x 1^{\text {Cre }} \beta$ cells were initially screened via immunofluorescence for various protein products important in their embryonic development and postnatal function, such as the Glut2 glucose transporter and MafA, MafB, Pdx1, and Nkx6.1 TFs (Artner et al., 2006; Fujitani et al., 2006; Matsuoka et al., 2004; Schaffer et al., 2013; Thorens, 2015). At P1, no change was observed in any of these $\beta$-cells markers. The levels of Glut2, MafA, and Pdx1 were reduced at the P7 and P28 time-points (Figure 2, columns 1-3). In contrast, Nkx6.1 protein levels were unchanged at all time points (Figure 2, Column 4) while MafB was elevated in $\beta$ cells after P7 (Figure 2, column 5). We found that the reduction in MafA and Pdx1 TFs in 6F; $P d x 1^{\text {Cre }}$ mice was not seen at the mRNA level (Figure S2A), suggesting that the Myt TFs do not transcriptionally control these key $\beta$-cell TF genes, and implying a strong post-transcriptional regulatory effect.

\section{Embryonic inactivation of Myt TFs potentiates stress-gene expression in P1 $\beta$}

\section{cells without activating early-stage stress sensors}

To potentially identify direct targets of the Myt-TFs, we next searched for transcriptomic differences between $6 F ; P d x 1^{\text {Cre }}$ and control $\beta$ cells. RNAseq analysis of P1 flow-sorted $\beta$ cells revealed 1,432 down- and 1,432 up-regulated genes (including pseudogenes, Table S2), classifiable into several distinct regulatory pathways by Gene-Set-Enrichment-Analysis (Figure S2B, $p<0.02$, adjusted) (Subramanian et al., 2005). Subsequent analysis focused on stress-response genes in the "protein processing in ER" category since these are associated with posttranscriptional control (Pan, 2013) and were amongst the most up-regulated in 6F; 
Pdx1 ${ }^{\text {Cre }} \beta$ cells [see Hspa1a, Hspa1b, HspH1, and Hspb1 expression in Table S2]. Importantly, mRNA expression of 12 of 13 up-regulated stress genes was verified in P1 and P14 6F; Pdx1Cre islets that had not undergone flow sorting (Figure 3A), eliminating the possibility that sorting stresses - such as the high level of the MIPdriven $\beta$-cell-specific eGFP marker and the processing by tissue dissociation and flow sorting - influenced their expression state.

Despite the up-regulated stress-gene expression in P1 6F; Pdx1 $1^{\text {Cre }} \beta$ cells, we detected no stress-associated ER lumen dilation using transmission electron microscopy (Figure S2C), or any general reduction in PERK-eIF2 $\alpha$-regulated protein translation in these P1 islets, although a slight translational reduction was detected at P14 (Figure S2D). In addition, Ire1 $\alpha$-mediated Xbp1 mRNA splicing was not increased in P1 6F; $P d x 1^{\text {Cre }}$ islets (Figure S2E). Likewise, stress-induced nuclear translocation of Foxo1 was not obvious until P14, when high blood-glucose levels were observed (Figure S2F). Lastly, there was no change in expression of earlyacting stress-pathway sensor-effectors that are classical Atf6 targets such as Xbp1, Hspa5, or Hsp90b1 (Figure S2G), nor HSF targets such as the Ccts (Figure S2G). Overall, we inferred that the substantial up-regulation in late-acting stress-response gene expression in $6 F ; P d x 1^{\text {Cre }}$ islets was not mediated by the early-acting UPR sensor-effectors, and consequently postulated that the Myt TFs normally work to directly repress transcription of these late-stage stress-pathway genes. Supporting this hypothesis, in silico analysis and data mining of published ChIP-seq data derived from fibroblasts and neuronal progenitors (Bellefroid et al., 1996; Mall et al., 2017; Vasconcelos et al., 2016) have identified several putative Myt TF binding sites 
(proposed AAGTT consensus, Bellefroid et al., 1996) within 5' cis-regulatory regions of Atf4, Hspa1a, Hspa1b, HspH1, and Dnajb1 (Figure 3B), although their significance to expression of these stress-pathway genes was not reported.

\section{Myt1 binds to cis-regulatory sequences within stress-response mediators}

To determine if the Myt TFs can exert regulatory control via the 5'-flanking control regions of Atf4, Dnajb1, Hspa1a, Hspa1b, and HspH1 genes proposed above, luciferase-reporter expression constructs driven by relatively short sequences spanning these elements were analyzed in co-transfection assays with Myt1 in HEK293T cells (Figure 3B). Myt1 significantly activated expression of the Hspa1a, Hspa1b, HspH1, and Atf4 reporters, but not Dnajb1. The more modest effect on Dnajb1-driven transcription could reflect the absence in our construct of an additional Myt-binding site detected at roughly $-6 \mathrm{kbp}$ in fibroblasts and neuronal cells (Mall et al., 2017)(Vasconcelos et al., 2016), because 5'-flanking control regions containing this putative binding site were for unknown reasons unclonable. Note that while we were probing the mechanisms for the transcriptionally repressive effects of Myt TFs on stress-pathway genes that we had detected in pancreatic $\beta$ cells, these out-of-context assays in HEK293T cells showed activation not repression, which we expected based on the similar "reversals" that occurred when testing the AAGTT motifs in artificial in vitro reporter-transfection assays (Bellefroid et al., 1996; Manukyan et al., 2018; Yee and Yu, 1998).

ChIP-PCR assays using islets were used to test directly for Myt1 binding within Hspa1a, Hspa1b, Hsph1, Dnajb1, and Atf4. Only Myt1 binding was analyzed for 
efficacy, as its zinc-finger DNA-binding region shares over $80 \%$ identity with that of Myt2/Myt3, and Myt1 antibodies are of high quality (Figure S3A). Acinar-cell chromatin, which does not express detectable Myt1, was the negative control (Figure S3B). Significant binding was observed within several Myt1-elementcontaining regions of Hspa1a, Hspa1b, Hsph1, and Atf4 (Figure 3C).

Myt1 binding was co-verified using a reporter driven by the Myt1 binding elements within the -435 to -402 bp region in Hspa1a. Myt1 responsiveness was analyzed using wild-type and mutated Myt-binding site constructs in cotransfection with a Myt1 DNA binding domain fused to the VP16 transactivation domain (i.e. Myt1ZF-VP16). Activation by Myt1ZF-VP16 in HEK293T cells was dependent on the presence of the AAGTT motifs (Figure 3D). Our data in pancreatic $\beta$ cells, combined with the ChIP-seq data from neuronal progenitors and fibroblasts (Mall et al., 2017)(Vasconcelos et al., 2016), leads to our supposition that Myt TF-based regulation of stress-pathway genes is functionally relevant in a variety of cell types.

\section{Over-expressing Hsps or Atf4 compromises postnatal islet $\beta$-cell proliferation,}

\section{survival, and function}

A tetracycline-inducible transgene was used to over-express $\mathrm{HspH} 1$, Hspa1b, Dnajb1, and eGFP [(termed $\mathrm{TetO}^{3 \mathrm{H}}$, Figure S4A); eGFP serves to identify the overexpressing cells]. The transgenic mouse driver to achieve HSP overexpression (Hsp-OE) was Rip rTTA, which produces the reverse tetracycline-controlled transactivator specifically in $\beta$ cells (Nir et al., 2007). Continuous doxycycline (Dox) administration in the drinking water from E16.5 resulted in 6-fold Hsp-OE in P2 
Rip ${ }^{\text {rTTA; }}$ TetO ${ }^{3 H}$ islets (Figure S4B). As expected from reports (Brennand et al., 2007; Cai et al., 2012; Dadi et al., 2014), Rip ${ }^{\text {rTTA }}$ only activated Hsp-OE in a portion of the $\beta$ cell pool, producing mosaic islets with intermixed overexpressing $\left(\mathrm{eGFP}^{+}\right)$and normal (eGFP-) cells (Figures 4A and S4C).

The proportion of $\mathrm{eGFP}^{+} \beta$ cells in Hsp-OE mice fell from $\sim 64 \%$ at $\mathrm{P} 2$ to $1-3 \%$ at P60 under continuous Dox-induced Hsp OE (Figure 4A). There was no transgene silencing (Figure S4D, E), but lowered proliferation rate in pre- and post-weaning Hsp-OE cells (Figure 4B). There was also increased apoptotic cell death by P35 (Figure 4C), although not at P10 (Figure S4F), indicated by detection of activated Caspase 3 in most Hsp-OE but not non-OE cells. While the MafA and MafB protein levels were not affected by Hsp-OE at several stages examined (Figure 4D, S4G, H), the levels of Glut2, insulin, and Pdx1 were reduced in P35 (Figure 4E-G) but not P10 Hsp-OE $\beta$ cells (Figure S4F-I). These results suggest that Hsp-OE recapitulates a portion of the $6 F$; Pdx1Cre phenotypes in proliferation, cell survival, and expression of some but not all $\beta$-cell factors.

To determine if Atf4 upregulation is responsible for the other portion of the 6F; Pdx1Cre phenotypes, ATF4-OE was activated by crossing Ins1Cre with Rosa26ATF4LoxTG mice. This resulted in $\sim 3$-fold ATF4-OE in P1 islets (Figure S5A-B). While mice with ATF4-OE displayed only slightly higher blood-glucose levels compared with controls at P8, most developed diabetes by five weeks of age (Figure S5C). These defects were preceded by an increased $\alpha$ - to $\beta$-cell ratio and decreased Glut2, insulin, MafA, and Pdx1 production in $\beta$ cells (Figure 5A-E and data not shown). The relative change in $\alpha$ to $\beta$ cells coincided with increased $\alpha$ and decreased $\beta$-cell 
proliferation (Figure 5F1-F3), without obvious $\beta$-cell apoptosis in 1-month or 3month old ATF4-OE islets (Figure S5D and data not shown). Additionally, ATF4-OE islets secreted an abnormally high amount of insulin at non-stimulating (basal) glucose concentrations, although substantial glucose-responsiveness was maintained (Figure 5G). Our observation is consistent with Atf4 inactivation potentiating GSIS (Yoshizawa et al., 2009).

Also to argue against the overexpression of any protein non-specifically compromising $\beta$-cell proliferation and/or gene expression, we over-produced tdTomato (tdT) in pancreatic $\beta$ cells using Pdx1CreER; Ai9 mice. Tamoxifen administration at E15.5 led to activation of $t d T$ expression in $\sim 50 \%$ of pancreatic $\beta$ cells (Liu et al., 2013). Unlike the OE of HspH1, Hspa1b, and DnajB1 or ATF4, tdT had no detectable effect on adult insulin or Pdx1 levels (Figure S5F). Collectively, these results demonstrate that the Myt TFs normally prevent the over-activation of Atf4, HspH1, Hspa1b, and DnajB1, which is consequential to postnatal mouse $\beta$-cell proliferation, survival, and function.

\section{Myt3 protein levels are induced in response to metabolic stress in diabetic $d b / d b$ mouse $\beta$ cells}

While inactivation of Myt TFs leads to dysregulated stress pathways, we also tested if there is a reciprocal tuning of Myt TFs levels in response to physiological stresses that are connected to stress responses, such as increased insulin secretion in obese diabetic mice. Comparing islets from 3-month old $d b /+$ control (euglycemic) and $d b / d b$ diabetic mice, we found no change in Myt1 or Myt2, but 
Myt3 protein levels were significantly up-regulated in $d b / d b \beta$ cells (Figure 6A-D). Intriguingly, Myt1, Myt2, and Myt3 transcript levels were not changed (Figure 6E), suggesting that the increased Myt3 protein level was acquired via posttranscriptional mechanisms. Notably, isolated $d b / d b$ islets were glucose responsive despite the overall hyperglycemic state of the mice (Figure 6F). These findings are consistent with a model that stress-responsive Myt3, together with constitutive Myt1 and Myt2, protect $\beta$ cells under metabolic stress.

\section{Downregulated MYT-TF levels are associated with stress-gene upregulation in human T2D islet $\beta$ cells}

The MYT1, 2, and 3 proteins were immunodetected in most functional human islet $\beta$ cells (Figure 6G-I). While MYT1 mostly appeared nuclear (Figure 6G1), MYT2 and MYT3 were cytoplasmic (Figure 6H1, I1). These factors were also substantially downregulated in most $\beta$ cells of T2D human donors (Figures 6G2, H2, I2), which were dysfunctional by whole-islet GSIS analysis (Figure S6A). However, some cytoplasmic MYT TF was still observed in some $\beta$ cells (Figure 6G2, H2, I2, arrows).

MYT TF mRNA expression was next examined in T2D human $\beta$ cells. A large challenge for this analysis is the heterogeneous nature of T2D, both between individual patients and between islets from the same patient, previously proposed to account for the poorly overlapping data between various samples (Wang and Kaestner, 2019). To avoid this issue, we utilized our recently devised RePACT algorithm to analyze single-cell expression data, which can reveal progressive 
movement along a pseudotime-trajectory from functional to dysfunctional $\beta$-cell state (Fang et al., 2019). There was a significant anti-correlation (adjusted $p=0.0007$ ) between the RePACT-inferred T2D-progression process and MYT3 mRNA levels, but not for MYT1 or MYT2 (Figure J1, J2, and Table S3). A positive correlation was observed between the T2D pseudo-timeline and expression of several ATFS (Figure 6J3, and Table S3), HSPA5 (BIP), HSP27, 40, and 90 family genes (Figure 6J4J8 and Table S3). These results provide further evidence for (at least) MYT3 influencing stress-gene expression in human $\beta$ cells. They also imply posttranscriptional mechanisms in regulating the MYT TF levels, as seen for Myt3 in $d b / d b$ islets

The reduced MYT TF expression levels in T2D $\beta$ cells likely result from the long-term effects of hyperglycemia and/or hyperlipidemia (Swisa et al., 2017). We therefore investigated the acute effects of both stressors. Treating human islets for 40 hours at a supra-physiological $16.7 \mathrm{mM}$ glucose concentration had little effect on GSIS (Figure 6K), but significantly and selectively up-regulated the MYT1 protein level in islet $\beta$ cells (Figure 6L-N, S6B, C). In contrast, lipotoxic $0.6 \mathrm{mM}$ palmitate treatment, which compromised but did not eliminate GSIS (Figure 60), rather specifically increased the level and nuclear localization of MYT3 [Figure 6P-R; compared to MYT1 and MYT2 (Figure S6D, E)]. Again, MYT1 or MYT3 transcript levels were unchanged by either treatment (Figure S6F), which further supports the significance of post-transcriptional mechanisms in regulating MYT TF protein levels. Thus, pathophysiological effectors of T2D $\beta$ cell dysfunction can influence MYT TF 
protein levels in human islets - most predominantly through post-transcriptional effects on MYT3.

\section{MYT TFs are required for human $\beta$-cell survival}

To provide further support for MYT TF action in stress-pathway gene regulation in human $\beta$ cells, siRNA-based $M Y T$ knockdown was performed in the human EndoC- $\beta \mathrm{H} 1$ cell line, which displays functional properties similar to primary human islet $\beta$ cells (Tsonkova et al., 2018). MYT1, 2, and 3 were all detected and MYT siRNA treatment effectively reduced their protein and mRNA levels in a majority of EndoC- $\beta \mathrm{H} 1$ cells (Figure 7). These conditions led to elevated ATF4, DNAJB1, HSPA1, and HSPH1 expression (Figure 7D) and increased $\beta$-cell death (Figure 7E), strongly supporting the integral and conserved role for the MYT TFs in stress-gene regulation in islet $\beta$ cells.

\section{Discussion}

Stress-survival response pathway activation needs to sufficient to allow proteomic homeostasis (misfolded protein clearance, chaperone activity, etc.) but not so high as to induce catastrophic cellular dysfunction and death. Such tuning is particularly important for islet $\beta$ cells which cannot be readily regenerated but produce stressors as part of their normal physiological function (Cao and Kaufman, 2014; Farley and Watkins, 2018; Fulda et al., 2010). Several molecular pathways by which cells activate stress-pathway gene expression have been established (Cao and Kaufman, 2014; Ma, 2013; Papa, 2012). Yet how cells maintain the appropriate 
amplitude to assure physiological, and not pathophysiological, expression is undetermined. We show here that the Myt TF family is required in controlling the response of $\beta$ cells to stress (Figure 7F). Given that ChIP analysis revealed Myt TF sites within lkely transcriptional control sequences of the Hspa1a, Hspa1b, Hsph1, and Atf4 genes in islet $\beta$ cells, neuronal progenitors (Vasconcelos et al., 2016)(Mall et al., 2017) and fibroblasts (Vasconcelos et al., 2016), it is possible that Myt TFs are involved in a general protective mechanism that allows stress-prone cells to function and survive.

\section{Myt TFs regulate several signaling pathways}

We have uncovered several cellular processes that the MYT TFs control in $\beta$ cells. Our earlier report of their inhibition of precocious Syt4 expression and, consequently, regulation of $\mathrm{Ca}^{2+}$ signaling and insulin secretion (Huang et al., 2018), adds to the present connection to the stress-response of postnatal $\beta$ cells. Additionally, we showed that loss-of Myt function deregulates over a dozen other genetic pathways (e.g., PI3K-AKT, Rap1, and Ras signaling; Figure S2B) that have well-established roles in $\beta$-cell proliferation and function (Elghazi et al., 2007; Font de Mora et al., 2003; Kelly et al., 2010). Given that manipulating Syt4 or stress-gene expression levels only partially recapitulates the overall phenotype arising from combined Myt1/Myt2/Myt3 loss-of function, we propose that the Myt family could be considered as a functional nexus that interconnects these intracellular responses to developmental and physiological signals. 


\section{Bidirectional connections between Myt TFs and stress-response pathways}

The absence of Myt TF in $6 F ; P d x 1^{\text {Cre }} \mathrm{P} 1$ islet $\beta$ cells resulted in precocious over-expression of late-stage stress-pathway genes, but they lacked concurrent signs of cellular stress response such as ER dilation or activation of some signature UPR and OSR genes. The conclusion is that the Myt TFs do not regulate the earlystage stress sensor/effectors (e.g., IRE1 and PERK), which can be activated for proteomic homeostasis in the presence of upregulated Myt TFs. Instead, these TFs mainly prevent the overactivation of the late-stage effectors (e.g., Atf4) that are more likely to trigger stress-incuced cell death/dysfunction (Hetz and Papa, 2018). Our ChIP and Myt-motif-driven transfection assays together strongly suggest that regulation is mediated by direct binding to 5'-flanking cis-regulatory sequences for at least Hspa1a, Hspa1b, HspH1, and Atf4, in agreement with results for Myt1 or Myt2 in fibroblasts and neuronal progenitors (Mall et al., 2017; Vasconcelos et al., 2016).

Our studies have revealed a complex cross-regulation between Myt TF and stress. In both murine and human $\beta$ cells, stress conditions that did not eliminate GSIS caused upregulation of MYT TF protein levels via post-transcriptional mechanisms. Specifically, this was observed in the context of Myt3 protein upregulation in $d b / d b$ obese mice, and MYT1 and MYT3 protein production and/or nuclear localization enhancement in human $\beta$ cells under short-term high glucose or palmitate treatment, respectively. Intriguingly, dysfunctional $\beta$ cells from T2D human donors had significantly reduced MYT3 and upregulated stress-gene transcription. This latter point, supported by our RePACT-based single-cell RNAseq, 
is consistent with results from conventional gene expression analyses, which showed down-regulation of MYT3 (Axelsson et al., 2017) and up-regulation of ATF1, ATF3, Hsp40, 70, 90, and 105 (Bugliani et al., 2013; Gunton et al., 2005; Hartman et al., 2004; Marselli et al., 2010; Segerstolpe et al., 2016).

Collectively, our findings support the following model (Figure 7F). In $\beta$ cells not suffering abnormally high-stress conditions, the Myt TFs ensure relatively low basal stress-gene expression. During metabolic stress, early-stage stress sensors/effectors (IRE1, PERK, Atf6, Nrf2, and etc.) were activated to maintain proteomic homeostasis (Cao and Kaufman, 2014; Hetz and Papa, 2018). The stressors also up-regulate Myt1/Myt3 protein levels to prevent over-activating the late-stage stress pathways (e.g., Atf4 and Hsps), which has the potential for inducing catastrophic $\beta$ cell failure and death. These mechanisms are only partially protective, because sustained stress can nonetheless cause its disablement, indicated by the reduced MYT TFs in T2D $\beta$ cells. This situation is notably similar to Foxo TFs, which become activated during early $\beta$-cell compensation but are later inactivated, for unknown reasons, during $\beta$ cell failure (Accili et al., 2016). It is plausible that exploring the mechanisms of Myt family regulation, perhaps first focused on the transcriptional and post-transcriptional regulation of MYT3, may provide ways of targeting MYT TFs to offset or prevent $\beta$ cell failure and T2D.

\section{Myt TFs regulate a subset of stress-response genes}

All stress-regulated genes are not upregulated in Myt-deficient $\beta$ cells. For instance, Hspa5, superoxide dismutase (Sod) and catalase (Cat) were unaltered in 6F; 
$P d x 1^{\text {Cre }}$ compared to control $\beta$ cells. This profile distinguishes the Myt TFs from other stress-activated TFs such as Foxo1 and Nrf2. Foxo1 potentiates MafA, $P d x 1$, ROS scavenging enzyme gene (i.e. Gpx, Sod, Cat) transcription to improve glucose sensing, insulin production, cell proliferation, and ROS removal (Kitamura et al., 2005; Talchai et al., 2012; Zhang et al., 2016). Nrf2 activation elevates the expression of antioxidant proteins for ROS degradation (Ma, 2013). We propose that the non-completely overlapping responses of Myt, Foxo, and Nrf2 TFs to cell stressors collectively provides for multimodal selectivity amongst the various kinds of cellular stress-survival machinery.

\section{Myt TFs may have both repressor and activator activities}

While Myt TFs were believed to predominantly repress gene transcription in vivo (Mall et al., 2017; Manukyan et al., 2018; Vasconcelos et al., 2016), ChIP-seq studies identified Myt1 or Myt2 motifs that were associated with activation by in vitro assays (Mall et al., 2017; Vasconcelos et al., 2016), suggesting a strong contextdependent ability for Myt TFs to act as activators or repressors. We found equal numbers of up- and down-regulated genes in $6 F ; P d x 1^{\text {Cre }} \beta$ cells from newborn mice (Table S2). Intriguingly, many up-regulated genes fell into the stress-response category, whereas down-regulated genes were generally associated with promotion of $\beta$-cell proliferation and function (Figure S2B). Thus, we speculate that Myt TFs can both directly activate genes required for $\beta$-cell compensation and repress those mediating cell failure. This proposal should be testable by orthogonal ChIPseq and RNAseq analysis in primary $\beta$ cells. 
Precisely how Myt TFs regulate transcription is unknown, although the Sin3 and Lsd1 co-regulators have been inferred as functional partners (Mall et al., 2017; Vasconcelos et al., 2016). The co-repressor Sin3, which has Sin3A and Sin3B paralogs, can recruit histone deacetylases (Grzenda et al., 2009) and was reported to interact with Myt TFs in neuronal and pancreatic $\beta$ cells (Romm et al., 2005; Scoville et al., 2015). Another repressor, Lsd1, or lysine-specific histone demethylase 1, was detected in a Myt1-containing transcriptional complex in neuronal cells (Yokoyama et al., 2014). Because Myt TFs may recruit Sin3 and/or Lsd1 to effect transcriptional repression (Vasconcelos et al., 2016; Yokoyama et al., 2014), direct experimentation, presumably starting with ChIP-type approaches, may distinguish the respective roles of Sin3 and Lsd1 and if they operate on independent or overlapping sets of genes.

In summary, we have uncovered a previously unknown role for the Myt TFs in controlling cellular response to stress in pancreatic islet $\beta$ cells, but potentially extendable to other cell types. Our data further suggest that the degree of repression tailors the stress response within a functionally favorable range to allow long-term cellular function and survival.

\section{Acknowledgement}

We thank Chunhua Dai and Alvin C. Powers of Vanderbilt Universtity Medical Center for assistance with the human islet studies. This study is supported by grants from NIDDK (DK065949 for GG and RS) and JDRF (1-2009-371 for GG). Confocal 
and TEM imaging were performed with VUMC Cell Imaging Shared Resource (supported by NIH grants CA68485, DK20593, DK58404, DK59637 and EY08126). We also thank the Islet Isolation and Procurement Core of Vanderbilt Medical Center for hormone assays (funded by DK20593).

\section{Author Contributions}

G.G., Y.L., R.S, A.N.B, and C.V.E.W. conceptualized the work and designed the experiments. R.H., Y.X., C.H., G.E.E., M.B., and G.G. did mouse characterization, gene expression, imaging, and secretion assays in mice. A. G. and M.B. did islet perifusion. R.H. and G.G did the reporter and ChIP assays in islets. E.W. and R.S. did MYT knockdown in human $\beta$ cells. C.W. and L.Y. analyzed gene expression in human $\beta$ cells. A.N.B., Y.X., and GG prepared primary human islets. All authors participated in manuscript writing.

\section{Declaration of competing interest}

The authors declare not competing interest.

\section{Materials \& Correspondence}

Correspondence and material request should be addressed to: Guoqiang.gu@vanderbilt.edu (615-936-3634). 


\section{References}

Accili, D., Talchai, S.C., Kim-Muller, J.Y., Cinti, F., Ishida, E., Ordelheide, A.M., Kuo, T., Fan, J., and Son, J. (2016). When beta-cells fail: lessons from dedifferentiation.

Diabetes Obes Metab 18 Suppl 1, 117-122.

Artner, I., Le Lay, J., Hang, Y., Elghazi, L., Schisler, J.C., Henderson, E., Sosa-Pineda, B., and Stein, R. (2006). MafB: an activator of the glucagon gene expressed in developing islet alpha- and beta-cells. Diabetes 55, 297-304.

Axelsson, A.S., Mahdi, T., Nenonen, H.A., Singh, T., Hanzelmann, S., Wendt, A., Bagge, A., Reinbothe, T.M., Millstein, J., Yang, X., et al. (2017). Sox5 regulates beta-cell phenotype and is reduced in type 2 diabetes. Nat Commun 8, 15652.

Bellefroid, E.J., Bourguignon, C., Hollemann, T., Ma, Q., Anderson, D.J., Kintner, C., and Pieler, T. (1996). X-MyT1, a Xenopus C2HC-type zinc finger protein with a regulatory function in neuronal differentiation. Cell 87, 1191-1202.

Brennand, K., Huangfu, D., and Melton, D. (2007). All beta cells contribute equally to islet growth and maintenance. PLoS Biol 5, e163.

Bugliani, M., Liechti, R., Cheon, H., Suleiman, M., Marselli, L., Kirkpatrick, C., Filipponi, F., Boggi, U., Xenarios, I., Syed, F., et al. (2013). Microarray analysis of isolated human islet transcriptome in type 2 diabetes and the role of the ubiquitin-proteasome system in pancreatic beta cell dysfunction. Mol Cell Endocrinol 367, 1-10.

Cai, Q., Brissova, M., Reinert, R.B., Pan, F.C., Brahmachary, P., Jeansson, M., Shostak, A., Radhika, A., Poffenberger, G., Quaggin, S.E., et al. (2012). Enhanced expression of VEGF-A in beta cells increases endothelial cell number but impairs islet morphogenesis and beta cell proliferation. Dev Biol 367, 40-54.

Cao, S.S., and Kaufman, R.J. (2014). Endoplasmic reticulum stress and oxidative stress in cell fate decision and human disease. Antioxid Redox Signal 21, 396-413. Chaari, A. (2019). Molecular chaperones biochemistry and role in neurodegenerative diseases. Int J Biol Macromol 131, 396-411.

Dadi, P.K., Vierra, N.C., Ustione, A., Piston, D.W., Colbran, R.J., and Jacobson, D.A. (2014). Inhibition of pancreatic beta-cell Ca2+/calmodulin-dependent protein kinase II reduces glucose-stimulated calcium influx and insulin secretion, impairing glucose tolerance. J Biol Chem 289, 12435-12445.

Elghazi, L., Rachdi, L., Weiss, A.J., Cras-Meneur, C., and Bernal-Mizrachi, E. (2007). Regulation of beta-cell mass and function by the Akt/protein kinase B signalling pathway. Diabetes Obes Metab 9 Suppl 2, 147-157.

Fang, Z., Weng, C., Li, H., Tao, R., Mai, W., Liu, X., Lu, L., Lai, S., Duan, Q., Alvarez, C., et al. (2019). Single-Cell Heterogeneity Analysis and CRISPR Screen Identify Key betaCell-Specific Disease Genes. Cell Rep 26, 3132-3144 e3137.

Farley, M.M., and Watkins, T.A. (2018). Intrinsic Neuronal Stress Response Pathways in Injury and Disease. Annu Rev Pathol 13, 93-116.

Fonseca, S.G., Gromada, J., and Urano, F. (2011). Endoplasmic reticulum stress and pancreatic beta-cell death. Trends Endocrinol Metab 22, 266-274.

Font de Mora, J., Esteban, L.M., Burks, D.J., Nunez, A., Garces, C., Garcia-Barrado, M.J., Iglesias-Osma, M.C., Moratinos, J., Ward, J.M., and Santos, E. (2003). Ras-GRF1 signaling is required for normal beta-cell development and glucose homeostasis. EMBO J 22, 3039-3049. 
Fujitani, Y., Fujitani, S., Boyer, D.F., Gannon, M., Kawaguchi, Y., Ray, M., Shiota, M., Stein, R.W., Magnuson, M.A., and Wright, C.V. (2006). Targeted deletion of a cisregulatory region reveals differential gene dosage requirements for $\mathrm{Pdx} 1$ in foregut organ differentiation and pancreas formation. Genes Dev 20, 253-266.

Fulda, S., Gorman, A.M., Hori, O., and Samali, A. (2010). Cellular stress responses: cell survival and cell death. Int J Cell Biol 2010, 214074.

Grzenda, A., Lomberk, G., Zhang, J.S., and Urrutia, R. (2009). Sin3: master scaffold and transcriptional corepressor. Biochim Biophys Acta 1789, 443-450.

Gu, G., Dubauskaite, J., and Melton, D.A. (2002). Direct evidence for the pancreatic lineage: NGN3+ cells are islet progenitors and are distinct from duct progenitors. Development 129, 2447-2457.

Gu, G., Wells, J.M., Dombkowski, D., Preffer, F., Aronow, B., and Melton, D.A. (2004).

Global expression analysis of gene regulatory pathways during endocrine pancreatic development. Development 131, 165-179.

Gunton, J.E., Kulkarni, R.N., Yim, S., Okada, T., Hawthorne, W.J., Tseng, Y.H., Roberson, R.S., Ricordi, C., O'Connell, P.J., Gonzalez, F.J., et al. (2005). Loss of ARNT/HIF1beta mediates altered gene expression and pancreatic-islet dysfunction in human type 2 diabetes. Cell 122, 337-349.

Guo, S., Dai, C., Guo, M., Taylor, B., Harmon, J.S., Sander, M., Robertson, R.P., Powers, A.C., and Stein, R. (2013). Inactivation of specific beta cell transcription factors in type 2 diabetes. J Clin Invest 123, 3305-3316.

Hartl, F.U., Bracher, A., and Hayer-Hartl, M. (2011). Molecular chaperones in protein folding and proteostasis. Nature 475, 324-332.

Hartman, M.G., Lu, D., Kim, M.L., Kociba, G.J., Shukri, T., Buteau, J., Wang, X., Frankel, W.L., Guttridge, D., Prentki, M., et al. (2004). Role for activating transcription factor 3 in stress-induced beta-cell apoptosis. Mol Cell Biol 24, 5721-5732.

Henry, C., Close, A.F., and Buteau, J. (2014). A critical role for the neural zinc factor ST18 in pancreatic beta-cell apoptosis. J Biol Chem 289, 8413-8419.

Hetz, C., and Papa, F.R. (2018). The Unfolded Protein Response and Cell Fate Control. Mol Cell 69, 169-181.

Hotamisligil, G.S., and Davis, R.J. (2016). Cell Signaling and Stress Responses. Cold Spring Harb Perspect Biol 8.

Huang, C., and Gu, G. (2017). Effective Isolation of Functional Islets from Neonatal Mouse Pancreas. J Vis Exp.

Huang, C., Walker, E.M., Dadi, P.K., Hu, R., Xu, Y., Zhang, W., Sanavia, T., Mun, J., Liu, J., Nair, G.G., et al. (2018). Synaptotagmin 4 Regulates Pancreatic beta Cell Maturation by Modulating the Ca(2+) Sensitivity of Insulin Secretion Vesicles. Dev Cell 45, 347361 e345.

Iurlaro, R., and Munoz-Pinedo, C. (2016). Cell death induced by endoplasmic reticulum stress. FEBS J 283, 2640-2652.

Juliana, C.A., Yang, J., Rozo, A.V., Good, A., Groff, D.N., Wang, S.Z., Green, M.R., and Stoffers, D.A. (2017). ATF5 regulates beta-cell survival during stress. Proc Natl Acad Sci U S A 114, 1341-1346.

Kelly, P., Bailey, C.L., Fueger, P.T., Newgard, C.B., Casey, P.J., and Kimple, M.E. (2010). Rap1 promotes multiple pancreatic islet cell functions and signals through 
mammalian target of rapamycin complex 1 to enhance proliferation. J Biol Chem $285,15777-15785$.

Kim, J.G., and Hudson, L.D. (1992). Novel member of the zinc finger superfamily: A C2-HC finger that recognizes a glia-specific gene. Mol Cell Biol 12, 5632-5639. Kitamura, Y.I., Kitamura, T., Kruse, J.P., Raum, J.C., Stein, R., Gu, W., and Accili, D. (2005). Fox01 protects against pancreatic beta cell failure through NeuroD and MafA induction. Cell Metab 2, 153-163.

Lipson, K.L., Fonseca, S.G., Ishigaki, S., Nguyen, L.X., Foss, E., Bortell, R., Rossini, A.A., and Urano, F. (2006). Regulation of insulin biosynthesis in pancreatic beta cells by an endoplasmic reticulum-resident protein kinase IRE1. Cell Metab 4, 245-254. Liu, J., Banerjee, A., Herring, C.A., Attalla, J., Hu, R., Xu, Y., Shao, Q., Simmons, A.J., Dadi, P.K., Wang, S., et al. (2019). Neurog3-Independent Methylation Is the Earliest Detectable Mark Distinguishing Pancreatic Progenitor Identity. Dev Cell 48, 49-63 e47.

Liu, J., Willet, S.G., Bankaitis, E.D., Xu, Y., Wright, C.V., and Gu, G. (2013). Non-parallel recombination limits Cre-LoxP-based reporters as precise indicators of conditional genetic manipulation. Genesis 51, 436-442.

Ma, Q. (2013). Role of nrf2 in oxidative stress and toxicity. Annu Rev Pharmacol Toxicol 53, 401-426.

Mall, M., Kareta, M.S., Chanda, S., Ahlenius, H., Perotti, N., Zhou, B., Grieder, S.D., Ge, X., Drake, S., Euong Ang, C., et al. (2017). Myt1l safeguards neuronal identity by actively repressing many non-neuronal fates. Nature 544, 245-249.

Manukyan, A., Kowalczyk, I., Melhuish, T.A., Lemiesz, A., and Wotton, D. (2018). Analysis of transcriptional activity by the Myt1 and Myt1l transcription factors. J Cell Biochem 119, 4644-4655.

Marselli, L., Thorne, J., Dahiya, S., Sgroi, D.C., Sharma, A., Bonner-Weir, S., Marchetti, P., and Weir, G.C. (2010). Gene expression profiles of Beta-cell enriched tissue obtained by laser capture microdissection from subjects with type 2 diabetes. PLoS One 5, e11499.

Matsuoka, T.A., Artner, I., Henderson, E., Means, A., Sander, M., and Stein, R. (2004). The MafA transcription factor appears to be responsible for tissue-specific expression of insulin. Proc Natl Acad Sci U S A 101, 2930-2933.

Nir, T., Melton, D.A., and Dor, Y. (2007). Recovery from diabetes in mice by beta cell regeneration. J Clin Invest 117, 2553-2561.

Ostling, P., Bjork, J.K., Roos-Mattjus, P., Mezger, V., and Sistonen, L. (2007). Heat shock factor 2 (HSF2) contributes to inducible expression of hsp genes through interplay with HSF1. J Biol Chem 282, 7077-7086.

Pan, T. (2013). Adaptive translation as a mechanism of stress response and adaptation. Annu Rev Genet 47, 121-137.

Papa, F.R. (2012). Endoplasmic reticulum stress, pancreatic beta-cell degeneration, and diabetes. Cold Spring Harb Perspect Med 2, a007666.

Ravassard, P., Hazhouz, Y., Pechberty, S., Bricout-Neveu, E., Armanet, M., Czernichow, P., and Scharfmann, R. (2011). A genetically engineered human pancreatic beta cell line exhibiting glucose-inducible insulin secretion. J Clin Invest 121, 3589-3597. Romm, E., Nielsen, J.A., Kim, J.G., and Hudson, L.D. (2005). Myt1 family recruits histone deacetylase to regulate neural transcription. J Neurochem 93, 1444-1453. 
Schaffer, A.E., Taylor, B.L., Benthuysen, J.R., Liu, J., Thorel, F., Yuan, W., Jiao, Y., Kaestner, K.H., Herrera, P.L., Magnuson, M.A., et al. (2013). Nkx6.1 controls a gene regulatory network required for establishing and maintaining pancreatic Beta cell identity. PLoS Genet 9, e1003274.

Schwartz, M.W., Guyenet, S.J., and Cirulli, V. (2010). The hypothalamus and ss-cell connection in the gene-targeting era. Diabetes 59, 2991-2993.

Scoville, D.W., Cyphert, H.A., Liao, L., Xu, J., Reynolds, A., Guo, S., and Stein, R. (2015). MLL3 and MLL4 Methyltransferases Bind to the MAFA and MAFB Transcription Factors to Regulate Islet beta-Cell Function. Diabetes 64, 3772-3783.

Segerstolpe, A., Palasantza, A., Eliasson, P., Andersson, E.M., Andreasson, A.C., Sun, X., Picelli, S., Sabirsh, A., Clausen, M., Bjursell, M.K., et al. (2016). Single-Cell

Transcriptome Profiling of Human Pancreatic Islets in Health and Type 2 Diabetes. Cell Metab 24, 593-607.

Sharma, R.B., O'Donnell, A.C., Stamateris, R.E., Ha, B., McCloskey, K.M., Reynolds, P.R., Arvan, P., and Alonso, L.C. (2015). Insulin demand regulates beta cell number via the unfolded protein response. J Clin Invest 125, 3831-3846.

Shen, J., Chen, X., Hendershot, L., and Prywes, R. (2002). ER stress regulation of ATF6 localization by dissociation of BiP/GRP78 binding and unmasking of Golgi localization signals. Dev Cell 3, 99-111.

Sies, H., Berndt, C., and Jones, D.P. (2017). Oxidative Stress. Annu Rev Biochem 86, 715-748.

Song, B., Scheuner, D., Ron, D., Pennathur, S., and Kaufman, R.J. (2008). Chop deletion reduces oxidative stress, improves beta cell function, and promotes cell survival in multiple mouse models of diabetes. J Clin Invest 118, 3378-3389.

Subramanian, A., Tamayo, P., Mootha, V.K., Mukherjee, S., Ebert, B.L., Gillette, M.A., Paulovich, A., Pomeroy, S.L., Golub, T.R., Lander, E.S., et al. (2005). Gene set enrichment analysis: a knowledge-based approach for interpreting genome-wide expression profiles. Proc Natl Acad Sci U S A 102, 15545-15550.

Sun, J., Cui, J., He, Q., Chen, Z., Arvan, P., and Liu, M. (2015). Proinsulin misfolding and endoplasmic reticulum stress during the development and progression of diabetes. Mol Aspects Med 42, 105-118.

Swisa, A., Glaser, B., and Dor, Y. (2017). Metabolic Stress and Compromised Identity of Pancreatic Beta Cells. Front Genet 8, 21.

Szabat, M., Page, M.M., Panzhinskiy, E., Skovso, S., Mojibian, M., Fernandez-Tajes, J., Bruin, J.E., Bround, M.J., Lee, J.T., Xu, E.E., et al. (2016). Reduced Insulin Production Relieves Endoplasmic Reticulum Stress and Induces beta Cell Proliferation. Cell Metab 23, 179-193.

Talchai, C., Xuan, S., Lin, H.V., Sussel, L., and Accili, D. (2012). Pancreatic beta cell dedifferentiation as a mechanism of diabetic beta cell failure. Cell 150, 1223-1234. Tennant, B.R., Islam, R., Kramer, M.M., Merkulova, Y., Kiang, R.L., Whiting, C.J., and Hoffman, B.G. (2012). The transcription factor Myt3 acts as a pro-survival factor in beta-cells. PLoS One 7, e51501.

Tennant, B.R., Vanderkruk, B., Dhillon, J., Dai, D., Verchere, C.B., and Hoffman, B.G. (2016). Myt3 suppression sensitizes islet cells to high glucose-induced cell death via Bim induction. Cell Death Dis 7, e2233. 
Thorens, B. (2015). GLUT2, glucose sensing and glucose homeostasis. Diabetologia 58, 221-232.

Trapnell, C., Roberts, A., Goff, L., Pertea, G., Kim, D., Kelley, D.R., Pimentel, H., Salzberg, S.L., Rinn, J.L., and Pachter, L. (2012). Differential gene and transcript expression analysis of RNA-seq experiments with TopHat and Cufflinks. Nat Protoc 7, 562-578.

Tsonkova, V.G., Sand, F.W., Wolf, X.A., Grunnet, L.G., Kirstine Ringgaard, A., Ingvorsen, C., Winkel, L., Kalisz, M., Dalgaard, K., Bruun, C., et al. (2018). The EndoCbetaH1 cell line is a valid model of human beta cells and applicable for screenings to identify novel drug target candidates. Mol Metab 8, 144-157.

Vasconcelos, F.F., Sessa, A., Laranjeira, C., Raposo, A., Teixeira, V., Hagey, D.W., Tomaz, D.M., Muhr, J., Broccoli, V., and Castro, D.S. (2016). MyT1 Counteracts the Neural Progenitor Program to Promote Vertebrate Neurogenesis. Cell Rep 17, 469483.

Wang, S., Zhang, J., Zhao, A., Hipkens, S., Magnuson, M.A., and Gu, G. (2007). Loss of Myt1 function partially compromises endocrine islet cell differentiation and pancreatic physiological function in the mouse. Mech Dev 124, 898-910.

Wang, Y.J., and Kaestner, K.H. (2019). Single-Cell RNA-Seq of the Pancreatic Islets--a Promise Not yet Fulfilled? Cell Metab 29, 539-544.

Yee, K.S., and Yu, V.C. (1998). Isolation and characterization of a novel member of the neural zinc finger factor/myelin transcription factor family with transcriptional repression activity. J Biol Chem 273, 5366-5374.

Yokoyama, A., Igarashi, K., Sato, T., Takagi, K., Otsuka, I.M., Shishido, Y., Baba, T., Ito, R., Kanno, J., Ohkawa, Y., et al. (2014). Identification of myelin transcription factor 1 (MyT1) as a subunit of the neural cell type-specific lysine-specific demethylase 1 (LSD1) complex. J Biol Chem 289, 18152-18162.

Yoshizawa, T., Hinoi, E., Jung, D.Y., Kajimura, D., Ferron, M., Seo, J., Graff, J.M., Kim, J.K., and Karsenty, G. (2009). The transcription factor ATF4 regulates glucose metabolism in mice through its expression in osteoblasts. J Clin Invest 119, 28072817.

Zhang, T., Kim, D.H., Xiao, X., Lee, S., Gong, Z., Muzumdar, R., Calabuig-Navarro, V., Yamauchi, J., Harashima, H., Wang, R., et al. (2016). Fox01 Plays an Important Role in Regulating beta-Cell Compensation for Insulin Resistance in Male Mice. Endocrinology 157, 1055-1070. 


\section{Figure legends}

Figure 1: Loss of $M y t$ function compromised functional $\beta$-cell mass. Mice were derived from inter-cross of $M y t 1^{F /+} ; M y t 2^{F /+} ; M y t 3^{F /+} ; P d x 1^{C r e}$ breeders or between $6 F$ and $M y t 1^{F / F} ; M y t 2^{F /+} ; M y t 3^{F / F} ; P d x 1^{C r e}$ mice. The $p$-values were type 2, 2-tailed t-test except in D and E (ANOVA). Error bars in all quantification panels, SEM. "n", the number of mice used. Also see Table S1 for data with sexes noted. For panels A-E, H, I, and Q, black bars or lines represent control data. Grey bars or lines represent mutant data.

(A) Glycemic phenotypes (left) and body weights (right). The controls include wildtype, $P d x 1^{C r e}$, and $6 F$ mice (see Table $\mathrm{S} 1$ for annotation).

(B) Plasma insulin levels before and 30 minutes after glucose challenge.

(C) Plasma glucagon (Gcg) levels in mice fasted overnight.

(D) Insulin tolerance tests. Presented are the blood glucose levels relative to that before insulin injection. $P$, one-way ANOVA.

(E) Perifusion-based insulin secretion assays. The track included sequential inductions by: G5.6 (5.6 mM glucose), G16.7, G5.6, G16.7 + $50 \mu \mathrm{M}$ IBMX (a cyclase inhibitor to increase intracellular cAMP levels), G5.6+KCl (20mM), and ended with G5.6. The $p$ value between G16.7-induced secretions is from one-way ANOVA.

$(F, G)$ Insulin detection with horse-radish peroxidase (HRP)-staining to visualize Insulin+ cells (brown, arrows). Scale bar $=50 \mu \mathrm{m}$. Insets in A and B, examples of islet stained for Pdx1, showing islet morphology.

(H) $\beta$-cell mass, mg $\beta$ cells per mouse or $\mathrm{mg} \beta$ cells per gram of body weight. 
(I-K) Mitotic indices (I) assayed with Ki67 expression (P7, not shown) or BrdU incorporation (P14, J, K. 2-day BrdU feeding) in $\beta$ cells. Arrows, examples of mitotic cells.

(L-Q) $\beta$ cells with activated Caspase 3 (Cas3, L-O) or TUNEL signals (P). The two rows are merged (top) and single (bottom) channels. Insets in 02 showed a cluster of Cas $^{+} \beta$ cells. In panel P2, scale bar $=20 \mu \mathrm{m}$, applicable to J-P.

Figure 2. The Myt TFs are required for sustained expression of several $\beta$-cell markers. Mice were derived from crosses between $6 F$ and $M y t 1^{F / F} ; M y t 2^{F /+} ; M y t 3^{F / F}$; $P d x 1^{\text {Cre }}$ mice. See Figure $\mathrm{S} 2$ for more related expression data.

(A-F) Images of each assayed protein. Co-expression of insulin and/or Pdx1 staining was used to locate $\beta$ cells but not shown [see inset in F5 (green: insulin, red: MafB) for an example]. Dotted-lines in some panels circled $\beta$-cell areas (column 5) or islets (F1-F4). Scale bar in F1=20 $\mu \mathrm{m}$, equal in all panels.

(G1-G5) Quantification of relative immunofluorescence of corresponding markers (in each column) at different stage, assayed with Image J. The error bars represent SEM. Three or four mice ("n") were used for each assay. P values (t-test) smaller than 0.05 were labeled.

Figure 3. Myt1 binds putative enhancers of several stress-response genes. See Figure S2 and S3 for more related data. Mice were derived from crosses between $6 F$ and $M y t 1^{F / F} ; M y t 2^{F /+} ; M y t 3^{F / F} ; P d x 1^{\text {Cre }}$ animals. Error bars in all quantification panels, SEM. 
(A) Real-time reverse transcription-PCR assays of several stress-gene mRNAs in $6 F$ control and 6F; $P d x 1^{\text {Cre }}$ islets. "n", number of mice assayed. All the expression changes except the three marked with "ns" are significant, with $p<0.05$ via T-test (type 2, 2 tails).

(B) Reporter assays of stress gene control elements. Diagrams on the left showed the $5^{\prime}$ distal regions of each gene assayed. The approximate length (kilo-base, kb) of used regulatory region was marked. Dark green lines, genomic region of genes. Light-blue rectangles, the stress-gene exons. Pink rectangles, firefly luciferase cDNA. Short blue lines, the AAGTT motifs. Red underlines, the amplicons used for ChIP-PCR in panel C. Arrowheads (Hspa1b, Dnajb1, and Atf4), DNA elements reported to bind with Myt1 and /or Myt2 in heterologous cells. The right side bars in panel C are relative reporter activities assayed in HEK293T cells. “*”, $p<0.02$ (t-test, type 2, 2tailed test. 4-8 independent assays). Error bars are SEM.

(C) ChIP-PCR assays of Myt1 enrichment on putative stress-gene enhancers. The locations of the PCR amplicons of each gene were marked in panel B. " $n$ " indicates number of immunoprecipitations. The $p$-values (type 2, 2-tailed t-test) smaller than 0.05 were marked. Acinar cells that do not express Myt1 were used as negative controls.

(D) Reporter assays using a putative Myt1-binding site on Hspa1a enhancers identified in ChIP assays (a2 in panel B). The motif, with wild-type and mutated sequences, was fused to a minimal CMV TATA box to produce reporters. The activator was a fusion protein between the C-terminal 4 zinc-fingers of Myt1 and a 
VP-16 activation domain. " $n$ ", the number of luciferases assays. " $p$ " value is from type 2, 2-tailed t-test.

Figure 4. Hsp over-expression (OE) compromised $\beta$-cell proliferation, identity, and survival. See Figure S4 for other characterization of Hsp-OE mice. Error bars in all quantification panels, SEM. In all quantification panels, "n", number of pancreata examined.

(A) The portion of Hsp-OE $\beta$ cells at several postnatal stages, monitored via the eGFP expression. The $p$-values (type 2, 2-tailed t-test) were marked.

(B) Mitotic activity of $\beta$ cells with (eGFP+ cells) or without Hsp OE (eGFP- cells). P10 (B1) cells were assayed via Ki67 expression. P21 (B2) and P26 (B3) cells via BrdU incorporation after BrdU feeding from water supply between P19-P21 or P21-P26, respectively. Scale bar $=20 \mu \mathrm{m}$. The $p$-values (type 2, 2-tailed t-test) were marked. (C-G) Expression of $\beta$-cell markers in P35 islets with Hsp OE. Merged and single channels were shown, with Image-J-aided quantification. E4 is a line scan (yellow thin line in E1, from top-left to bottom-right), showing the Glut2 intensity along the borders of over-expressing (O) and non-over-expressing (W) cells. The P-values (type 2, 2-tailed t-test) smaller than 0.05 were marked on top of each assay. The circles in C2, D2, E2, and E3 mark the outline of whole $\beta$ cells. Scale bars $=20 \mu \mathrm{m}$.

Figure 5. ATF4 OE compromised $\beta$-cell gene expression and insulin secretion. ATF4 OE was initiated in $\beta$ cells using the Ins1 ${ }^{\text {Cre }}$ and Rosa26-ATF4LoxTG mouse lines. 
See Figure S5 for crossing and other characterization of HSP-OE mice. Error bars, SEM.

(A-E) Detection of several $\beta$-cell markers. Controls are Rosa26-ATF4LoxTG pancreata. Inset in D1 is an example to show how $\alpha$ (blue) and $\beta$ (red) cells were identified. In E, three to four $(n=3-4)$ pancreata were quantified. The P-values (type 2, 2-tailed ttest) smaller than 0.05 were marked. Scale bar in D5 $=20 \mu \mathrm{m}$, applicable to all panels.

(F) Mitotic assays via Ki67 staining. "n", number of pancreata quantified. The Pvalues (type 2, 2-tailed t-test) were marked. Scale bar $=20 \mu \mathrm{m}$.

(G) GSIS assays of P14 control and ATF4-OE islets. "n", the number of secretion assays, from 3 mice (with each has at least two technical duplicates). The P-value is from type 2, 2-tailed t-test.

Figure 6. Metabolic stress upregulates Myt (MYT) TF proteins in mouse and human $\beta$ cells while T2D downregulates MYT TFs but upregulates stress-gene transcripts. See Figure S6 and Table S3 for more characterization of human islets. Error bars in all quantification panels, SEM.

(A-F) Myt TF expression at protein (A-D) and mRNA (E) levels in $\beta$ cells/islets of $d b /+$ and $d b / d b$ mice that maintain GSIS (F). Inset in C2 showed $\beta$ cells (Insulin+, white) that express Myt3 (red). "n", number of mice examined. The P-values (type 2, 2-tailed t-test) smaller than 0.05 were marked. Scale bar in C2 $=20 \mu \mathrm{m}$, applicable from A-C. 
(G-I) MYT TF levels in functional (G1, H1, and I1) and non-functional (G2, H2, and I2, arrows point to several MYT $\beta$ cells) human islet $\beta$-cells. Representative results from three donors, with merged channels between MYT and Insulin signals shown. Scale bar $=20 \mu \mathrm{m}$.

(J) RePACT-analysis of MYT and stress gene transcription in $\sim 35,000 \beta$ cells of six normal and 3 T2D islet donors. X-axis, pseudotime trajectory of T2D progression (left to right). Y-axis, relative gene expression. Each dot represents a $\beta$-cell subpopulation. The blue line represents average gene expression trajectory. The blue shades indicate range of gene expression with 95\% confidence levels.

(K-N) GSIS [K, under $3.3 \mathrm{mM}$ (G3.3) and $20 \mathrm{mM}$ (G20) glucose] and MYT1 production of human $\beta$ cells after 40-hour treatment of 17 mM (G17) glucose. " $n$ " in panel K, number of GSIS assays. " $n$ " in $N$, batches of islets used for MYT1 quantification. A merged MYT1/Insulin and a single MYT1 channel were shown. The marked p-values were type 2, 2-tailed t-test. Scale bar $=20 \mu \mathrm{m}$.

(O-R) Same as K-N except 0.6 mM palmitate (Pal) was used instead of G17.

Figure 7. MYT TFs is required for human $\boldsymbol{\beta}$-cell line survival. All assays were done three days after cell re-plating. Error bars in all quantification panels, SEM.

(A) MYT TF detection in EndoC- $\beta \mathrm{H} 1$ cells. Individual and merged channels were all presented. Scale bar $=20 \mu \mathrm{m}$. 
(B) Representative images of siRNA-based MYT1 KD three days after siRNA transfection. Arrows, examples of MYT1+ nuclei. Arrowheads in B2, examples of cells with low MYT1 signal. Scale bar $=20 \mu \mathrm{m}$.

(C) Staining and quantification of MYT TFs in viable EndoC- $\beta \mathrm{H} 1$ cells after MYT KD. MYT1, 2, 3 signals were combined into one single channel $(\mathrm{C} 1, \mathrm{C} 2)$ and quantified with Image J (C3). The $p$-value was from type 2, 2-tailed t-test. Scale bar $=20 \mu \mathrm{m}$.

(D) Effects of MYT KD on the transcription of several stress genes in EndoC- $\beta \mathrm{H} 1$ cells. “*”, $p<0.05$, from type 2, 2-tailed t-test.

(E) Propidium Iodide (PI) assays of cell death three days after siRNA KD. Bright field and PI fluorescence were shown (E1 and E2, a field transfected with control RNA. E3 and E4, a field transfected with MYT siRNA). The quantification was by counting the number of PI+ cells per cell cluster. Scale bar $=100 \mu \mathrm{m}$. The $p$-value was from type 2, 2-tailed t-test.

(F) A model depicting Myt functions in $\beta$-cell stress response. Under normal conditions (left box), sub-threshold stressors induce low level of cellular stress and stress-gene expression, which reduce cellular stress. The Myt TFs, may or may not rely on stress for expression, ensure low stress-gene expression to prevent $\beta$-cell dysfunction and death. Higher stressors (right box) induce higher cellular stress and stress-gene expression for protein homeostasis while also induced Myt1/Myt3, which again prevent late-stage stress-gene over-activation and $\beta$-cell dysfunction and/or death. 


\section{STAR methods:}

\section{Mice derivation and usage}

Mouse usage followed protocols approved by the Vanderbilt University IACUC for GG, in compliance with regulations of AAALAC. All mice were euthanized by isoflurane inhalation, followed by decapitation or cervical dislocation.

Wild-type CD1 (ICR) mice were from Charles River Laboratories. The C56BL/6J, Ai9 [Gt(ROSA)26Sortm9(CAG-tdTomato)Hze], Rip-rTTA [Tg(Ins2-rtTA)2Efr/J], Rosa26-ATF4LoxTG (B6;129X1-Gt(ROSA)26Sortm2(ATF4)Myz/J), and Ins1 ${ }^{\text {Cre }}[\mathrm{B} 6(\mathrm{Cg})-$ Ins1 ${ }^{\text {tm1.1(cre)Thor } / \mathrm{J}]}$ mice were purchased from the Jackson laboratories. The Pdx1Cre and $P d x 1^{C r e E R}$ mice were described in (Gu et al., 2002). The derivation of $M y t 1^{F /+}$, $M y t 2^{F /+}$, and $M y t 3^{F /+}$ mice were described in (Huang et al., 2018; Wang et al., 2007). The $\mathrm{TetO}^{3 \mathrm{H}}$ mice were derived by pronuclear injection, with a DNA construct made by ligating a bi-directional Tet-ON-3G promoter (Clontech), the coding sequences of Hspa1b, HspH1, Dnajb1, eGFP and SV40 early poly-adenylation signals as indicated in Figure S4A. The entire construct was sequence-verified. Note that H2A peptidebreakers were included so that each mRNA could make two proteins (Figure S4A). Five independent transgenic lines were derived, with founders directly crossing with Rip ${ }^{\text {rTTA }}$ mice to establish stable lines.

For producing the Myt triple mutants, Myt1F/F; Pdx1 ${ }^{\text {Cre }}$ mice $[\sim 50 \%$ CD1 background, based on crossing history (Wang et al., 2007)] were crossed with Myt2 ${ }^{\mathrm{F} /+}$ mice [ 50\% CD1 background]. Myt1 ${ }^{\mathrm{F} /+}$; Myt2 $2^{\mathrm{F} /+} ; \mathrm{Pdx} 1^{\mathrm{Cre}}$ mice were then 
crossed with $M y t 3^{F /+}$ animals ( $50 \%$ CD1 background) to obtain $M y t 1^{F /+}$; $M y t 2^{F /+}$; $M_{y t 3} 3^{F /+}$ Pdx $1^{\text {Cre }}$ mice, which were out-crossed twice with CD1 mice in order to ensure a mixed CD1 genetic background. The $M y t 1^{F /+} ; M y t 2^{F /+} ; M y t 3^{F /+} ; P d x 1^{\text {Cre }}$ mice were then intercrossed. From $\sim 20$ litters of mice, two wild-type (WT), four Pdx1Cre, five $M y t 1^{F / F} ; M y t 2^{F / F} ; M y t 3^{F / F}$ (denoted as $6 F$ ), and four $M y t 1^{F / F} ; M y t 2^{F / F} ; M y t 3^{F / F}$; Pdx1 $1^{\text {Cre }}$ (denoted as $6 F ; P d x 1^{C r e}$ ) mice were obtained. No phenotypic differences were found amongst the WT, $P d x 1^{C r e}$, and $6 \mathrm{~F}$ mice (Figure 1 and Table S1). Thus, most of the studies use $6 F$ (littermates of $6 F ; P d x 1^{\text {Cre }}$ mice) as controls, derived from

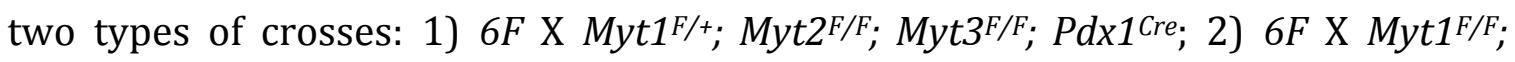
$M y t 2^{F /+} ; M y t 3^{F / F} ; P d x 1^{C r e}$. These mice were euglycemic and fertile up to 8-month after birth, allowing the above crossing. $6 F$ littermates were used as controls.

For Hsp OE, TetO ${ }^{3 H}$ mice (males and females) were crossed with Rip ${ }^{\text {rTTA }}$ mice (females and males). The day of vaginal plug appearance was counted as embryonic day 0.5 (E0.5). To induce Hsp OE, pregnant mice were put on water supply with 200 microgram/ml Dox from E16.5 ad lib until the day of tissue collection. For initial Hsp OE characterization, via eGFP expression, all five lines were used. Two were euthanized because of their low $(<10 \%)$ penetrance of eGFP production in $\beta$ cells. Three had similar portions of $\beta$ cells expressing eGFP, so that one was randomly chosen for all studies presented here. For testing the potential silencing of Rip-rTTA or $\mathrm{TetO}^{3 \mathrm{H}}$ transgenes in adult ages, isolated islets from Hsp-OE; Rip-rTTA mice were treated with Dox at 2-month of age without prior exposure. For ATF4 OE, a similar crossing scheme as above was used, except that the Rosa26-ATF4LoxTG and Ins1Cre 
mouse lines were used and no Dox was introduced. Rosa26-ATF4LoxTG/+ and Ins $1^{\text {Cre }}$ littermates were all included as controls.

\section{Blood glucose, plasma hormone assays, and insulin tolerance test (ITT)}

Fasting glucose levels were read via tail snip after 6-hour (before one month old) or overnight (after one month old) fasting. For plasma insulin assay, retroorbital blood collection was used. For ITT, mice were fasted for 4 hours. Insulin was injected at 1 unit/kg. Blood glucose was then measured. The blood glucose levels were read with a NovaMaxplus meter using blood from tail tip.

\section{Pancreatic islet isolation}

Pancreata were directly digested (for P1, P7, and P14 pancreata) (Huang and $\mathrm{Gu}, 2017$ ) or perfused (for pancreata older than 2 weeks) with $0.5 \mathrm{mg} / \mathrm{ml}$ Type IV collagenase dissolved in Hanks Balanced Salt Solution (HBSS) with $\mathrm{Ca}^{2+} / \mathrm{Mg}^{2+}$. After digestion at $37^{\circ} \mathrm{C}$, lysates were washed in RPMI 1066 with $5.6 \mathrm{mM}$ glucose and $10 \%$ fetal bovine serum (i.e. RPMI-FBS) 4 times. Islets were hand-picked in RPMI-FBS for downstream usage.

\section{Islet insulin secretion assays}

For static insulin secretion, the $\%$ of total insulin secreted within a 45 -minute window was measured unless noted. Hand-picked islets were allowed to recover in RPMI-FBS for 2 hours or overnight. Islets were washed twice with pre-warmed KRB solution (2.8 mM glucose, $102 \mathrm{mM} \mathrm{NaCl}, 5 \mathrm{mM} \mathrm{KCl,} 1.2 \mathrm{mM} \mathrm{MgCl}$, $2.7 \mathrm{mM} \mathrm{CaCl}$, 20 
mM HEPES, 5 mM NaHCO 3 , and $10 \mathrm{mg} / \mathrm{ml}$ BSA, pH 7.4) and then incubated in KRB $\left(37^{\circ} \mathrm{C}\right)$ for one hour, washed with pre-warmed KRB once more. 10-15 islets were then transferred into each of the wells of 12-well plates with $1 \mathrm{ml}$ pre-warmed KRB to start the secretion assays. For all assays, four or more mice of each genotype were used for islet isolation, with islets from two or more mice mixed and examined as 23 technical replicas. Insulin was measured with an Elisa kit from ALPCO following manufacturer protocol. Assays from human islets were performed with the same way, except the basal glucose was $3.3 \mathrm{mM}$.

For perifusion assays, hand-picked islets were incubated overnight in RPMI with $10 \mathrm{mM}$ glucose for recovery. Islets were then placed in a 1-ml perifusion chamber, equilibrated in KRB with $5.6 \mathrm{mM}$ glucose for $30 \mathrm{~min}$ and then challenged with $16.7 \mathrm{mM}$ glucose, $5.6 \mathrm{mM}$ glucose $+50 \mu \mathrm{M}$ IBMX, and $5.6 \mathrm{mM}$ glucose $+20 \mathrm{mM}$ $\mathrm{KCl}$. The perifusion fractions were collected in 3-min intervals at $1 \mathrm{ml} / \mathrm{min}$ flow rate and assayed for insulin by radioimmunoassay.

\section{Real-time PCR-based gene expression assays}

RNA was prepared from hand-picked islets with TRIzol (Life Technologies) and a DNA free RNATM kit (Zymo Research). 20-100 ng total RNAs were then used for cDNA preparation and real-time PCR, utilizing SYBR green master mix of the BioRad system, with oligos listed in Table S3. Note that the human ATF4 and mouse Atf4 coding sequences are conserved, making it possible to assay both cDNAs with a single pair of oligos (Table 3). 


\section{Protein pulse labeling assays.}

Hand-picked islets were allowed to recover for $\sim 2$ hours in RPMI-FBS media. Islets were then transferred to media with 1:4 mix of RPMI-1640: Cys /Met-depleted DMEM with 20 mM glucose and 10\% FBS, supplemented with ${ }^{35}$ S-labeled Cys/Met. After four hours, labeled islets were incubated in RPMI-FBS for 15 minutes, washed in PBS, and lysed for gel-electrophoresis and quantification (aided with Image J). The number of cells from each islet sample was determined via real-time PCR to compare the relative copy number of genomic DNA. Lysates of same numbers of cells were loaded into each lane of the protein gels for comparison, followed by gel drying and film exposure.

\section{Immunolabeling, $\beta$-cell mass assays, and transmission electron microscopy}

Antibody staining followed standard procedures. Briefly, pancreatic or other issues were dissected. They would be: 1) directly frozen, sectioned, and then fixed in 4\% paraformaldehyde for 15 minutes followed by permeabilization and antibody staining with Ki67 or MafA antibodies; 2) fixed in 4\% paraformaldehyde overnight at $4{ }^{\circ} \mathrm{C}$, washed with PBS 3 times, frozen, and sectioned for transcription factor and Glut2 staining; 3) fixed in 4\% paraformaldehyde overnight at $4{ }^{\circ} \mathrm{C}$, washed with PBS 3 times, and prepared as paraffin sections. In this case, the tissue will be sequentially dehydrated with $45,70,80,95$, and $100 \%$ ethanol, and twice with xylene, and embedded in paraffin. For hormone staining, the paraffin block will be sectioned, rehydrated with the above xylene and ethanol solutions in reverse 
orders, and staining with antibodies. Small tissues $(<0.5 \mathrm{~mm}$ in each dimension) can be directly fixed. Large pancreata (older than P14) were cut into 5-10 small pieces and fixed. Six and $20 \mu \mathrm{m}$ thick sections were prepared for paraffin and frozen tissues, respectively. Sections were stained with antibodies diluted in basal solution (1X Phosphate Buffered Saline $+0.1 \%$ triton $100+0.1 \%$ Tween-20 $+0.1 \%$ BSA + 0.05\% donkey serum). Antibodies used were listed in Key Resource Table, with dilution from 1:500 to 1:5000, depending on the antibody used and amount of tissue on each slide ( $0.1 \mathrm{ml}$ antibody mix for each slide). For imaging, laser-scanning microscopy (LSM) was used. When expression levels of a protein between samples were compared, slides/cells were processed side-by-side, and images were captured utilizing identical optical/electronic settings. For protein level quantification, LSM images taken under identical parameters were selected for Image J-based particle quantification. Double blind tests were used.

Transmission electron microscopy (TEM) followed established procedure. Briefly, islets were fixed in $2.5 \%$ glutaraldehyde in $0.1 \mathrm{M}$ cacodylate buffer $(\mathrm{pH}$ 7.4) overnight at room temperature. Islets were then washed and treated in $1 \%$ osmium tetroxide in $0.1 \mathrm{M}$ cacodylate buffer for 1 hour. Islets were then washed, embedded, thin-sectioned for imaging. For unbiased ER examination, image capture and quantification were performed under double-blind settings.

For quantifications of $\beta$-cell mass and replication index throughout the pancreas, the pancreatic block was sectioned at $20 \mu \mathrm{m}$ intervals. One third to one fifth of all sections were labeled and scanned using Aperio ScanScope or an Olympus 
X51. B-cell mass was then calculated based on the total pancreas weight and the percentage of tissues area that labeled for insulin.

\section{Beta-cell mitosis and apoptosis assays}

For mice younger than P10, frozen pancreatic sections were prepared for Ki67 staining and quantification. For older mice, multiple-day BrdU feeding via drinking water (50 ng/ml) were performed. The pancreata were recovered, sectioned, and stained for \% of Ins+ cells that incorporated BrdU. Up to 5\% of all islet sections were quantified in each mice. Alternatively, hand-picked islets were dissociated into single cells, spun onto glass slides, and stained for marker expression and counting. For apoptotic cell counting, similar scheme was used.

\section{Human islet culture}

Hand-picked human islets (>95\% purity) were cultured in CRML-1066 media with $10 \%$ FBS and $3.3 \mathrm{mM}$ glucose overnight. For high glucose treatment, media were switched to $10 \%$ FBS with 3.3 or $20 \mathrm{mM}$ glucose. For palmitate treatment media were switched to that containing $0.5 \%$ BSA or $0.6 \mathrm{mM}$ palmitate with $5 \%$ FBS. Islets were cultured for $\sim 40$ hours and assayed for GSIS and mRNA expression. For immunoassays, islets were washed 2X with PBS and dissociated into small cell clusters (single to $\sim 20$-cell) and cytospun onto slides for after-fixation and staining/imaging.

\section{Gene expression in human EndoC- $\beta \mathrm{H} 1$ cells}


Human EndoC- $\beta \mathrm{H} 1$ cells were grown in DMEM containing $5.6 \mathrm{mM}$ glucose, 2\% BSA, $50 \mu \mathrm{M}$ 2-mercaptoethanol, 10 mM nicotinamide, $5.5 \mu \mathrm{g} / \mathrm{mL}$ transferrin, 6.7 ng/mL selenite, 100 units $/ \mathrm{mL}$ penicillin, and 100 units $/ \mathrm{mL}$ streptomycin (Ravassard et al., 2011). For siRNA transfection [with a mix of three individual siRNAs (20 nM each)], dissociated cells were incubated with siRNA (with RNAiMax) for 5 minutes before plating. Gene expression assays were performed three days after infection or transfection by directly lysing cells on plates for RNA assays or recovered, cyto-spun onto glass slides for protein expression assays. Human islets were purchased from IIDP or obtained from the Clinical Islet Transplantation Laboratory, University of Louisville, KY. Hand-picked islets were dissociated into single cells and Cyto-spun onto glass slides for antibody staining.

\section{Protein abundance assay at per cell levels}

Stained cells (with immunofluorescence, dilution were marked on the key reagent Table) using tissue sections or dissociated islet cells that were cyto-spun onto glass slides. Mutant/OE and control slides were processed side by side. Confocal images were taken under identical parameters using non-saturating conditions. Image J was then used to quantify the fluorescence intensity. For Glut2 and insulin assays, the averaged fluorescence intensity within selected areas was used. For transcription factor assays, nuclei were circled and assayed for intensity. For background subtraction, areas outside the islets and inter-nuclear areas were assayed. Three to four pancreata were assayed, with three to ten representative microscopic areas assayed. 


\section{Luciferase assays}

The luciferase reporter construction followed routine molecular cloning process. Briefly, BAC clones carrying the Hsp genomic regions were purchased from Oakland Children's Hospital. PCR were then used to amplify the genomic fragments indicated in Figure 5A and inserted into a vector containing firefly luciferase-eGFP fusion and a PolyA signal. The constructs were then sequenced to ensure correct sequences. Note that for unknown reasons we could not clone DNA fragments that contain a putative Myt1 and Myt2 binding motif $\sim 6$ kilobase upstream of the Dnajb1 transcription initiation site (Mall et al., 2017; Vasconcelos et al., 2016). The functional significance of this motif was therefore not tested.

For making firefly luciferase reporters with the 33-bp Myt1-binding sites of Hspa1a, a minimal CMV promoter was synthesized and ligated with the Hspa1a enhancer and the firefly luciferase reporter. The artificial Myt1ZF-VP16 constructs were made by PCR fragment ligation: the 4-zinc finger region was amplified with PCR, using a full length Myt1 cDNA as template; the VP-16 region was PCR-amplified with the rTTA cDNA as template. The oligos used were in Table S3. Luciferase assays followed established protocols. Briefly, HEK293T cells were transfected with Myt1 overexpressing or control plasmids, together with firefly luciferase reporters and a Renilla luciferase internal control. Cells were then lysed two days after transfection to assay the firefly and Renilla luciferase activity using a Dual Luciferase Assay kit (Perkin Elmer) following the manufacturer's protocol. 


\section{Putative Myt-binding site identification and ChIP-PCR assays}

The putative Myt1 and Myt2 binding sites were identified by examining the supplementary tables in (Mall et al., 2017; Vasconcelos et al., 2016) based on ChIPseq data and in silico search of the AAGTT motives recognized by the Myt TFs. ChIP assays used a Magna-CHIPTM HiSens kit from Millipore, following manufacturers recommendation. Briefly, adult islets and acinar clusters were handpicked, fixed in $1 \%$ formaldehyde for 14 minutes and washed $2 \mathrm{X}$ with cold PBS. Islets were then frozen for storage. When $\sim 3000$ islets were obtained, they were thawed and dounced into single cells in lysis buffer provided in the kit, and sonicated to $\sim 100$ 400 base pair fragments. Chromatin preparation from acinar cells followed the same process. The immunoprecipitation was done using $1 \mu \mathrm{g}$ purified antibodies per 0.4 $\mu$ g chromatin overnight. Oligos used in the following real-time PCR were listed in Table S4. Oligos from albumin promoter regions were used as controls.

\section{Sample size and statistical analysis}

All experiments contained at least two biological replicas and two technical replicas, so that all assays had at least 4 independent experiments. Statistical analyses utilized standard Student's $t$-test for pairwise comparisons or one-way ANOVA for comparing multiple groups of data points. A $p$-value of 0.05 or lower was considered significant.

\section{RNAseq Data analysis}

The original RNA-seq data were deposited in ArrayExpress under ID code EMTAB-2266 (https://www.ebi.ac.uk/arrayexpress/experiments/E-MTAB-2266/) 


\section{and E-MTAB-6615 (https://www.ebi.ac.uk/arrayexpress/experiments/E-MTAB-}

$\underline{6615 /)}$. The data were generated with purified $\beta$ cells using Mip-eGFP expression as a surrogate for insulin production (Huang et al., 2018). After downloading the data, raw reads were processed and analyzed with TopHat and Cufflinks to determine the relative abundance of gene expression at each stages, reported as $\log 2$ transformed FPKM (Fragments Per Kilobase of transcript per Million mapped reads, Table S2)(Trapnell et al., 2012). To avoid excluding false negative genes, we included all genes with adjusted p-value smaller than 0.05 . We also included other genes with a difference above 2 -fold and a p-value smaller than 0.02 .

For a full description of RePACT (regressing principle components for the alignment of continuous trajectory)-based human $\beta$-cell analysis, please refer to the star methods of (Fang et al., 2019). Briefly, we used Dropseq to generate massively parallel single cell transcriptome data $(\sim 39,000 \beta$ cells, from 1,800 human islet $)$. In RePACT, we first performed PCA to reduce the dimension of transcriptome data. Next, we used regression analysis to draw two optimal trajectory lines reflecting the T2D-relevant variation. In this study, we used the top 10 PCs as predictors. The numeric projection of each cell on the T2D trajectory (T2D index) served as a measurement of the degree to which the cell has transformed during disease development. We then binned the cells into a number of pseudo-states according to the index values. By comparing cells from different pseudo-states, RePACT greatly improved the statistical power to identify gene signatures for T2D status in $\alpha$ or $\beta$ cell. 


\section{KEY RESOURCES TABLE}

\begin{tabular}{|c|c|c|}
\hline REAGENT or RESOURCE & SOURCE & IDENTIFIER \\
\hline \multicolumn{3}{|c|}{ Antibodies (with fold of dilution indicted) } \\
\hline $\begin{array}{l}\text { 488-donkey anti Guinea Pig } \\
(1: 1000)\end{array}$ & $\begin{array}{l}\text { Jackson } \\
\text { Immunoresearch }\end{array}$ & $\begin{array}{l}\text { 706-545-148 } \\
\text { RRID:AB_2340472 }\end{array}$ \\
\hline $\begin{array}{l}\text { 488-donkey anti goat igG } \\
(1: 1000)\end{array}$ & $\begin{array}{l}\text { Jackson } \\
\text { Immunoresearch }\end{array}$ & $\begin{array}{l}\text { 705-545-147 } \\
\text { RRID:AB_2336933 }\end{array}$ \\
\hline $\begin{array}{l}\text { Alexa Fluor® } 647 \text { AffiniPure } \\
\text { Donkey Anti-Guinea Pig IgG } \\
(\mathrm{H}+\mathrm{L})(1: 1000)\end{array}$ & $\begin{array}{l}\text { Jackson } \\
\text { Immunoresearch }\end{array}$ & $\begin{array}{l}\text { 706-605-148 } \\
\text { RRID:AB_2340476 }\end{array}$ \\
\hline $\begin{array}{l}\text { Alexa Fluor } \AA 488 \text { AffiniPure } \\
\text { Donkey Anti-Rabbit IgG }(H+L) \\
(1: 1000)\end{array}$ & $\begin{array}{l}\text { Jackson } \\
\text { Immunoresearch }\end{array}$ & $\begin{array}{l}\text { 711-545-152 } \\
\text { RRID:AB_2313584 }\end{array}$ \\
\hline $\begin{array}{l}\text { Alexa Fluor® } 647 \text { AffiniPure } \\
\text { Donkey Anti-Rabbit }(1: 1000)\end{array}$ & $\begin{array}{l}\text { Jackson } \\
\text { Immunoresearch }\end{array}$ & $\begin{array}{l}\text { 711-605-152 } \\
\text { RRID:AB_2492288 }\end{array}$ \\
\hline $\begin{array}{l}\text { Alexa Fluor® } 647 \text { AffiniPure } \\
\text { Donkey Anti-Mouse IgG }(H+L) \\
(1: 1000)\end{array}$ & $\begin{array}{l}\text { Jackson } \\
\text { Immunoresearch }\end{array}$ & $\begin{array}{l}\text { 715-605-150 } \\
\text { RRID:AB_2340862 }\end{array}$ \\
\hline $\begin{array}{l}\text { Alexa Fluor@ } 594 \text { AffiniPure } \\
\text { Donkey Anti-Mouse }(1: 1000)\end{array}$ & $\begin{array}{l}\text { Jackson } \\
\text { Immunoresearch }\end{array}$ & $\begin{array}{l}\text { 715-585-150 } \\
\text { RRID:AB_2340854 }\end{array}$ \\
\hline $\begin{array}{l}\text { Alexa Fluor® } 594 \text { AffiniPure } \\
\text { Donkey Anti-Goat IgG }(H+L) \\
(1: 1000)\end{array}$ & $\begin{array}{l}\text { Jackson } \\
\text { Immunoresearch }\end{array}$ & $\begin{array}{l}\text { 705-585-003 } \\
\text { RRID:AB_2340432 }\end{array}$ \\
\hline $\begin{array}{l}\text { Alexa } 647 \text { AffiniPure Rabbit Anti- } \\
\text { Syrian Hamster IgG }(H+L) \\
(1: 1000)\end{array}$ & $\begin{array}{l}\text { Jackson } \\
\text { Immunoresearch }\end{array}$ & $\begin{array}{l}\text { 307-605-003 } \\
\text { RRID:AB_2339601 }\end{array}$ \\
\hline Rat anti-BrdU & ABcam & $\begin{array}{l}\text { Ab-6326 } \\
\text { RRID:AB_305426 }\end{array}$ \\
\hline biotin anti Rat $(1: 1000)$ & $\begin{array}{l}\text { Jackson } \\
\text { Immunoresearch }\end{array}$ & $\begin{array}{l}\text { 712-065-151 } \\
\text { (RRID: N/A) }\end{array}$ \\
\hline Cy3-Donkey anti-mouse (1:1000) & $\begin{array}{l}\text { Jackson } \\
\text { Immunoreserach }\end{array}$ & $\begin{array}{l}\text { 715-165-150 } \\
\text { RRID:AB_2340813 }\end{array}$ \\
\hline Cy3-streptavidin (1:1000) & Vector laboroatories & SA-1300 (RRID: N/A) \\
\hline Cy5- streptavidin (1:1000) & Vector laboroatories & SA-1500 (RRID: N/A) \\
\hline FITC anti Rabbit (1:1000) & $\begin{array}{l}\text { Jackson } \\
\text { Immunoresearch }\end{array}$ & $\begin{array}{l}\text { 711-095-152 } \\
\text { RRID:AB_2315776 }\end{array}$ \\
\hline Goat anti-Pdx1 (1:2000) & ABcam & $\begin{array}{l}\text { AB47383 } \\
\text { RRID:AB_2162359 }\end{array}$ \\
\hline Goat anti-insulin (1:500) & Santa Cruz & $\begin{array}{l}\text { sc-7839 } \\
\text { RRID:AB_2296108 }\end{array}$ \\
\hline Guinea pig anti insulin $(1: 1000)$ & Dako & $\begin{array}{l}\text { A0564 } \\
\text { RRID: N/A }\end{array}$ \\
\hline Rabbit anti-Myt1 (1:1000) & This paper & $\mathrm{N} / \mathrm{A}$ \\
\hline
\end{tabular}




\begin{tabular}{|l|l|l|}
\hline Mouse anti-glucagon (1:5000) & Millipore & $\begin{array}{l}\text { MabN238 } \\
\text { RRID:NA }\end{array}$ \\
\hline Rabbit anti-Pdx1 (1:5000) & ABcam & $\begin{array}{l}\text { AB47267 } \\
\text { RRID:AB_777179 }\end{array}$ \\
\hline Rabbit anti-Nkx6.1 (1:5000) & Gift of P. Serup & NA \\
\hline Rabbit anti-MafB (1:1000) & Gift of R. Stein & NA \\
\hline $\begin{array}{l}\text { Rabbit anti-Cleaved Caspase } 3 \\
(1: 500)\end{array}$ & SYSY & $\begin{array}{l}\text { \#105173 } \\
\text { RRID:AB_887838 }\end{array}$ \\
\hline Rabbit anti-glucagon (1:100) & ABcam & $\begin{array}{l}\text { AB92517 } \\
\text { RRID:AB_10561971 }\end{array}$ \\
\hline Rabbit anti-Ki67(1:500) & Abcam & $\begin{array}{l}\text { Ab 15580 } \\
\text { RRID:AB_443209 }\end{array}$ \\
\hline Guinea pig anti-Myt2 & This lab & NA \\
\hline Rat anti-Myt3 & This lab & NA \\
\hline Bacterial and Virus Strains & & \\
\hline Bl-21 & Vanderbilt MPB Core & NA \\
\hline DH5-alpha & Vanderbilt MPB Core & NA \\
\hline Xl-1 & Vanderbilt MPB Core & NA \\
\hline Biological Samples & & A9418 \\
\hline Bovine serum albumin & Sigma & $017-000-121$ \\
\hline Donkey Serum & Jackson & S10250_AB_2337258 \\
\hline Fetal Bovine Serum & Atlanta Biologicals & \\
\hline Chemicals, Peptides, and other key reagents & C5138 \\
\hline $\begin{array}{l}\text { Collagenase from Clostridium } \\
\text { histolyticum }\end{array}$ & Sigma & D2650 \\
\hline DMSO & Sigma & D9891 \\
\hline Doxycycline & Sigma & D9542 \\
\hline dapi & Sigma & P154 \\
\hline Adenosine, periodate oxidized & Sigma & PIHA01250 \\
\hline paraformaldehyde & Sigma & C5138-5G \\
\hline Millicell & Millipore & 18080085 \\
\hline Trypsin & Sigma & 10777019 \\
\hline $\begin{array}{l}\text { SuperScript III Reverse } \\
\text { Transcriptase }\end{array}$ & Thermo & Lucigen \\
\hline $\begin{array}{l}\text { RNaseOUT Recombinant } \\
\text { Ribonuclease Inhibitor }\end{array}$ & Thermo & \\
\hline $\begin{array}{l}\text { RNaseOUT Recombinant } \\
\text { Ribonuclease Inhibitor }\end{array}$ & Thermo & \\
\hline $\begin{array}{l}\text { Tn5 enzyme for methylome DNA } \\
\text { tagmentation }\end{array}$ & Home made & \\
\hline T4 DNA Polymerase & NEB & \\
\hline Ampligase & & \\
\hline Critical Commercial Assays & & \\
\hline & & \\
\hline
\end{tabular}


bioRxiv preprint doi: https://doi.org/10.1101/773846; this version posted September 18, 2019. The copyright holder for this preprint (which was not certified by peer review) is the author/funder. All rights reserved. No reuse allowed without permission.

\begin{tabular}{|l|l|l|}
\hline High capacity cDNA synthesis & Applied BIosystems & 4368814 \\
\hline SYBER Green qpcr mix & Biorad & 1705060 \\
\hline
\end{tabular}


Figure 1:

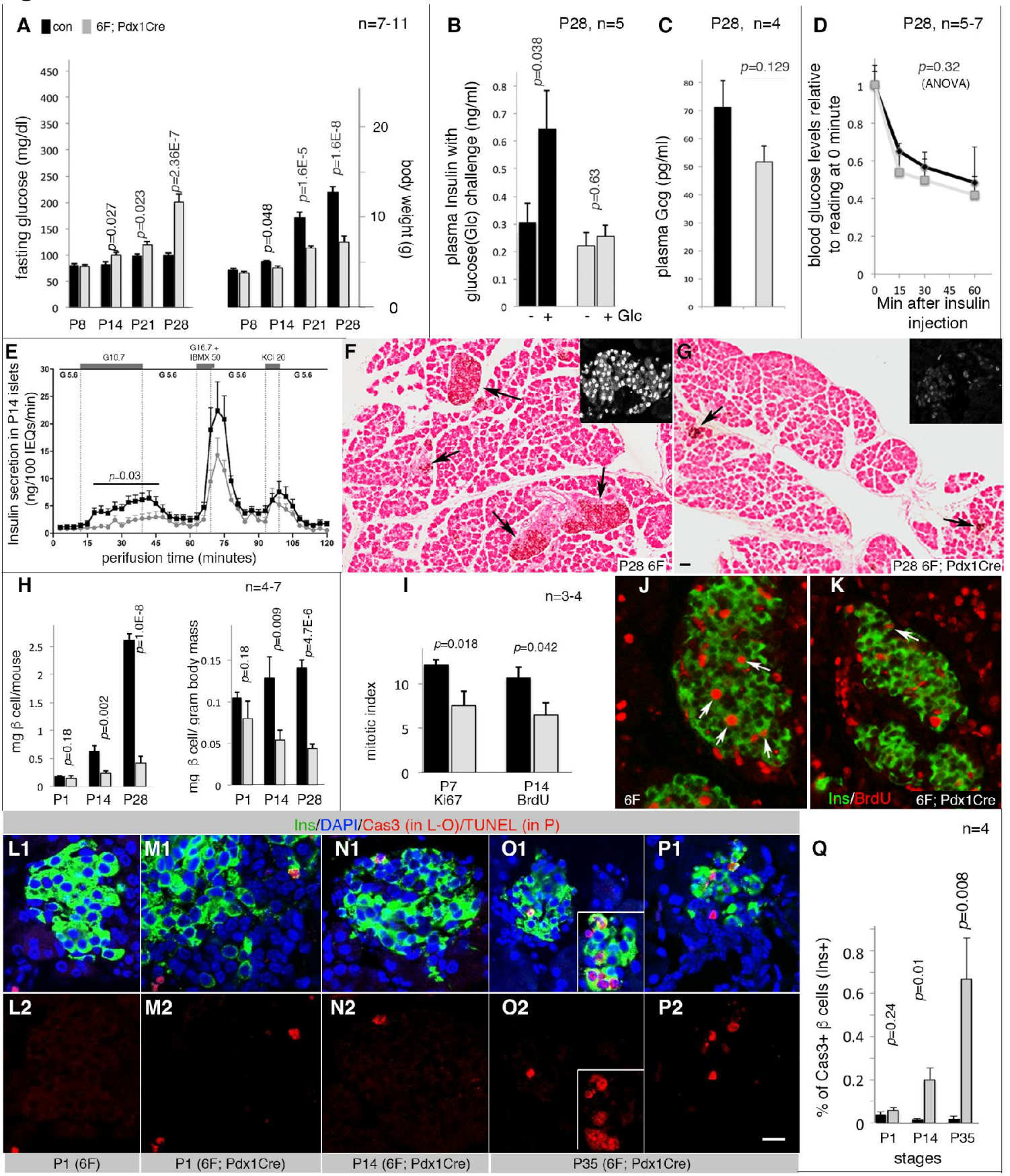


Figure 2;

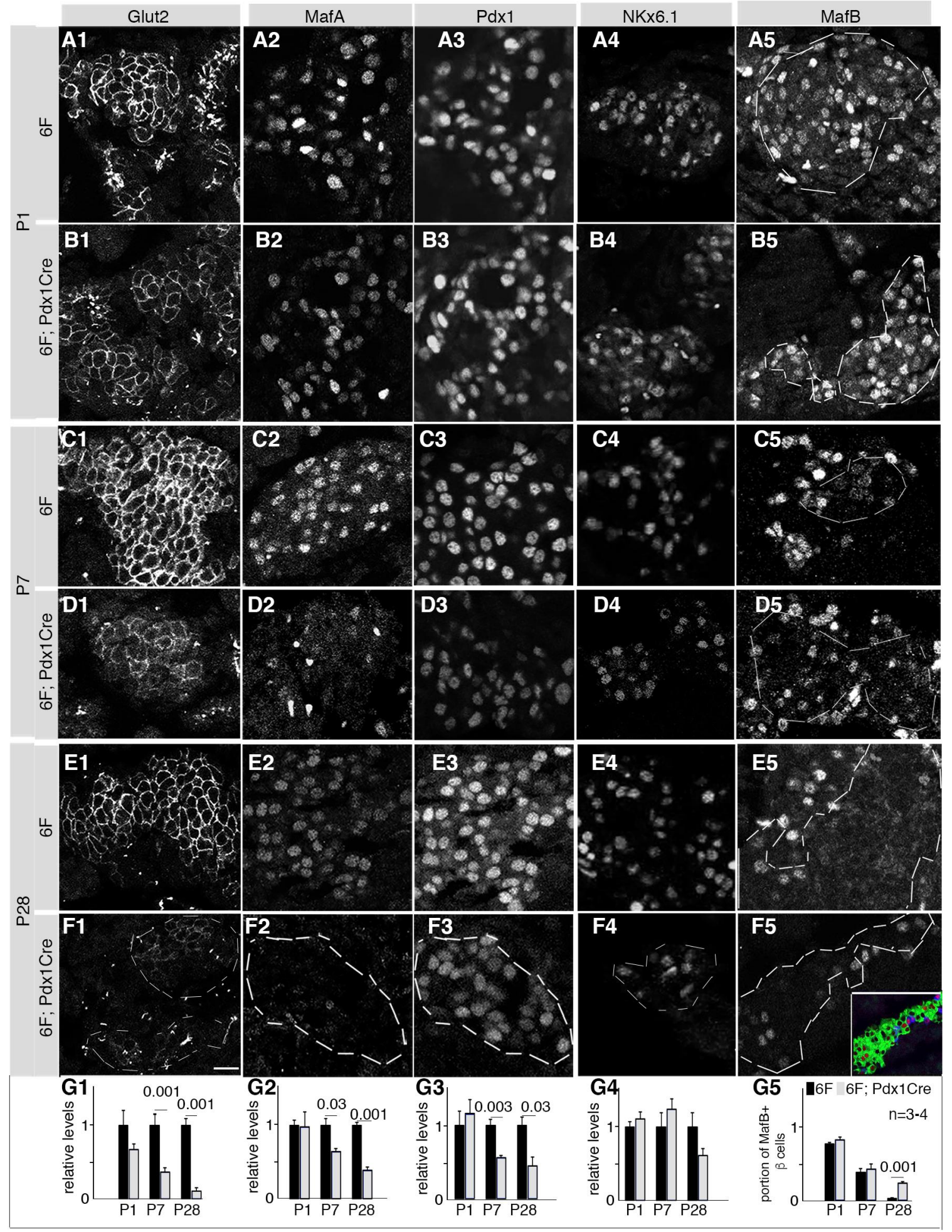


Figure 3:

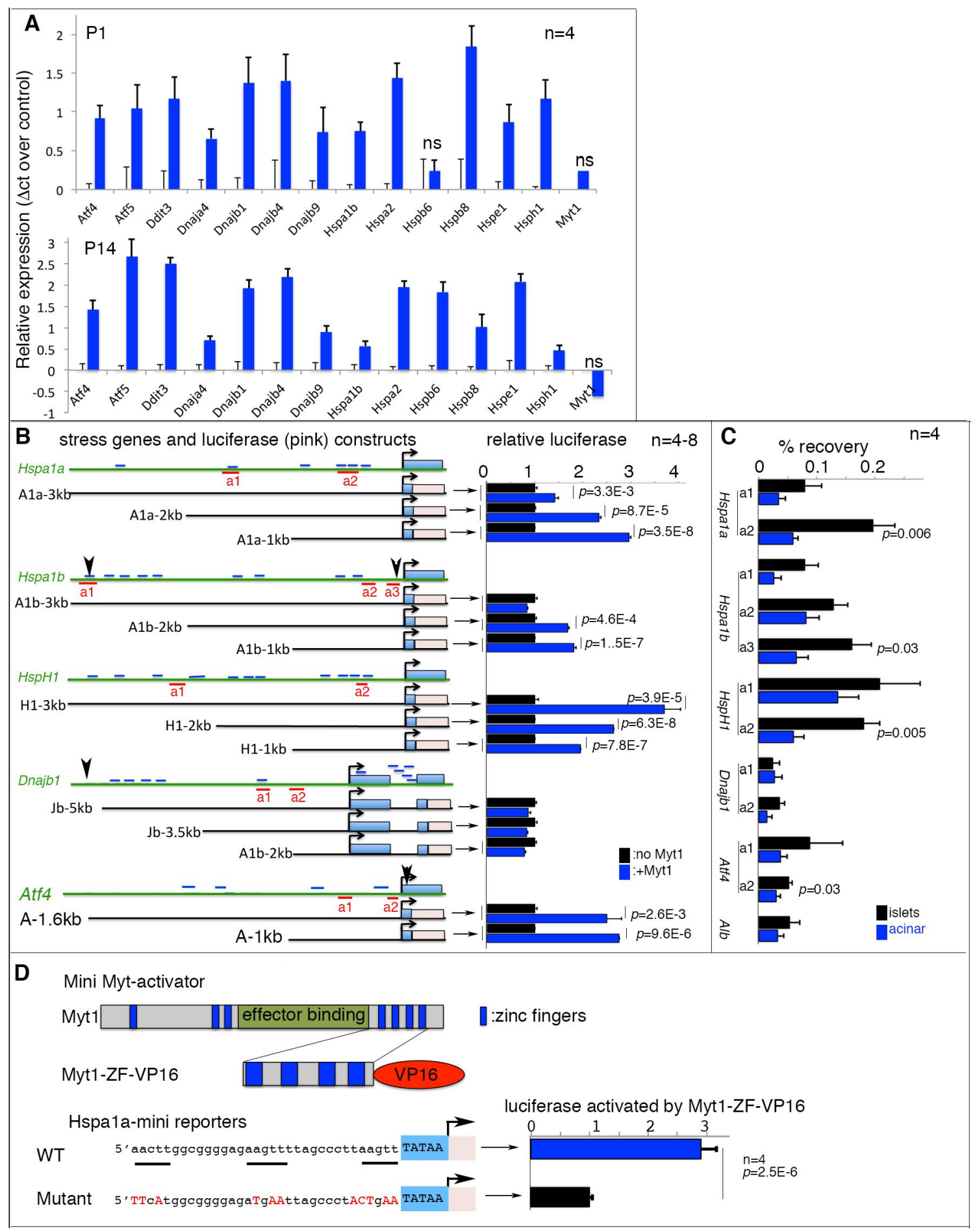


Figure 4:

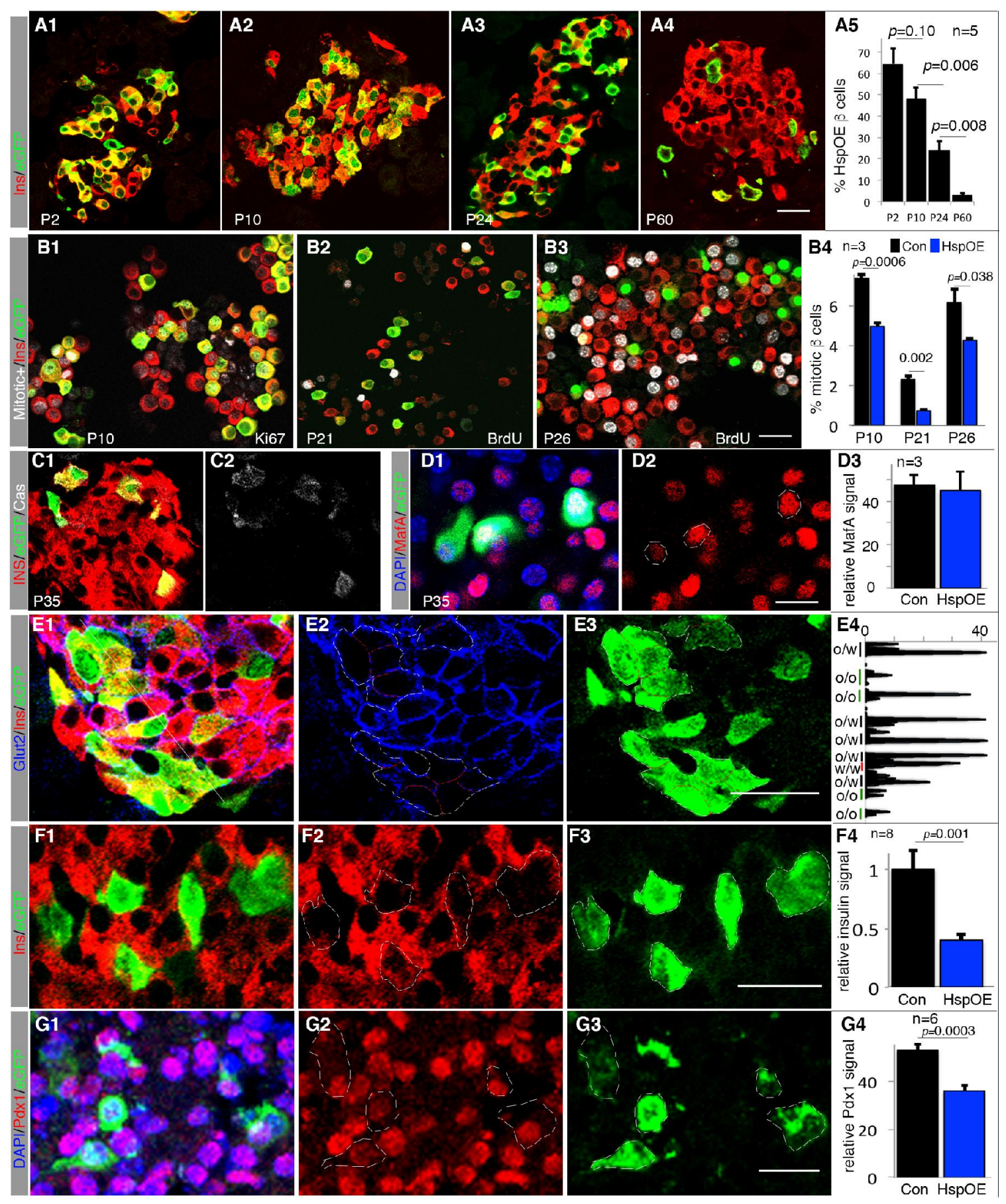


Figure 5:

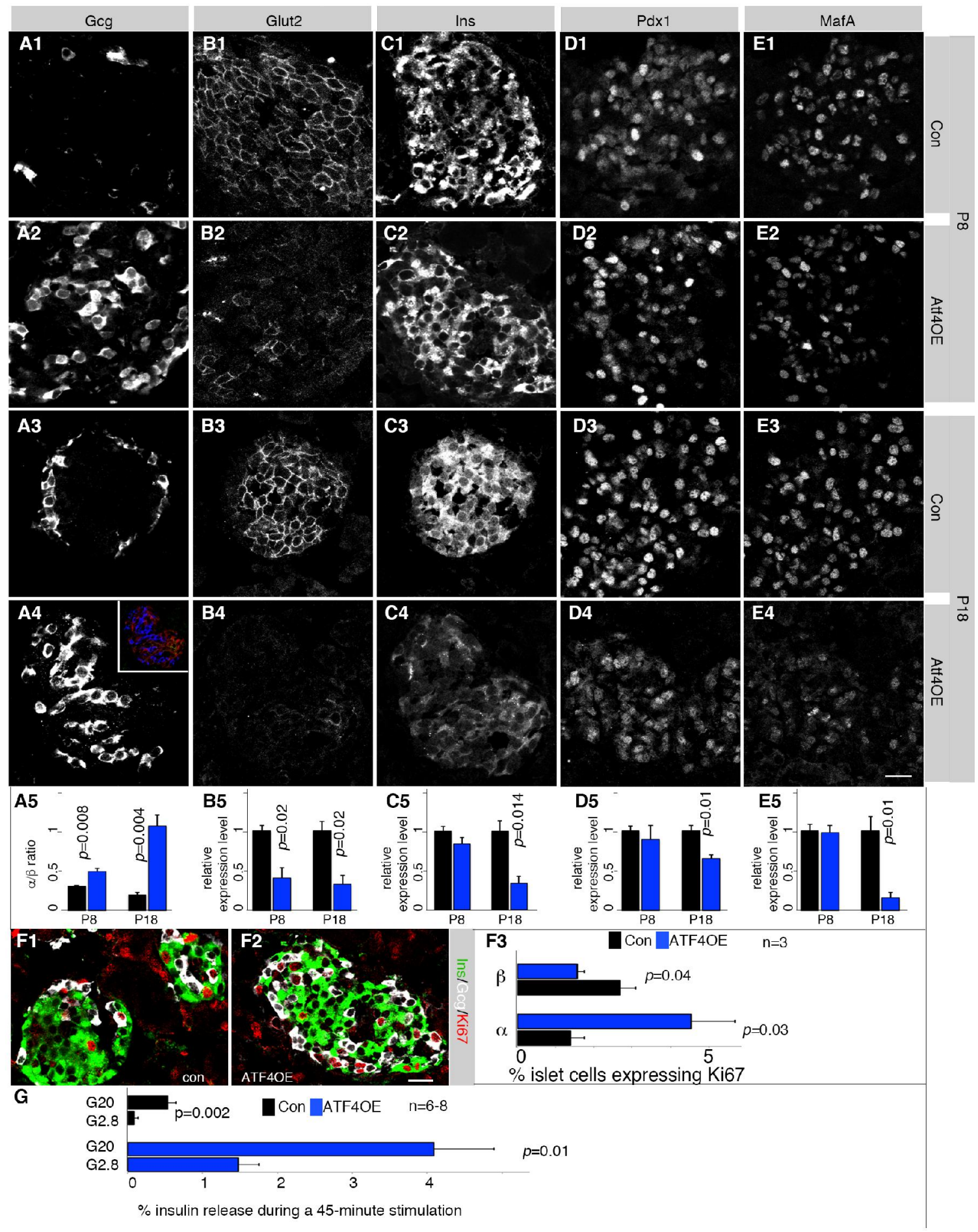


Figure 6:

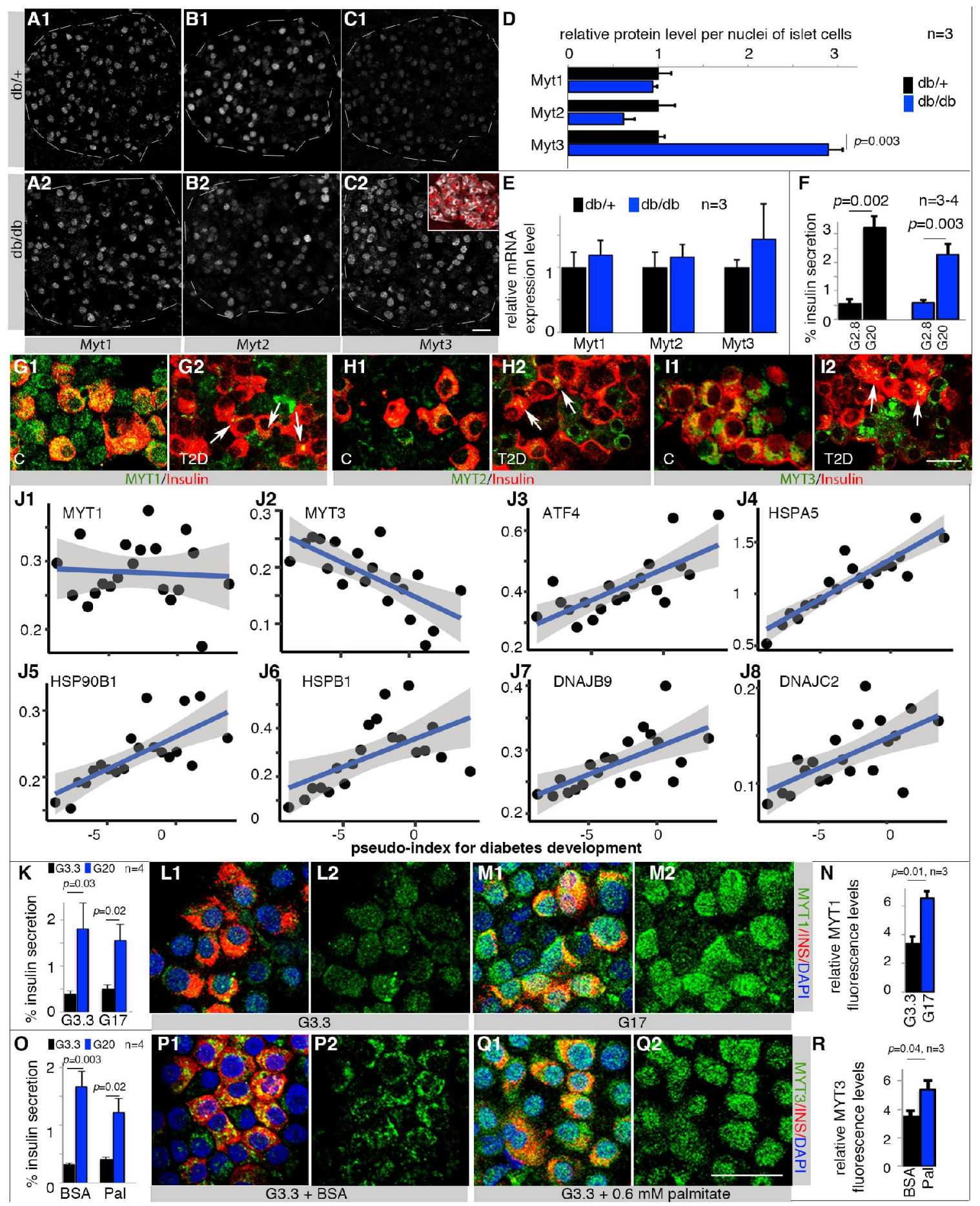


Figure 7:

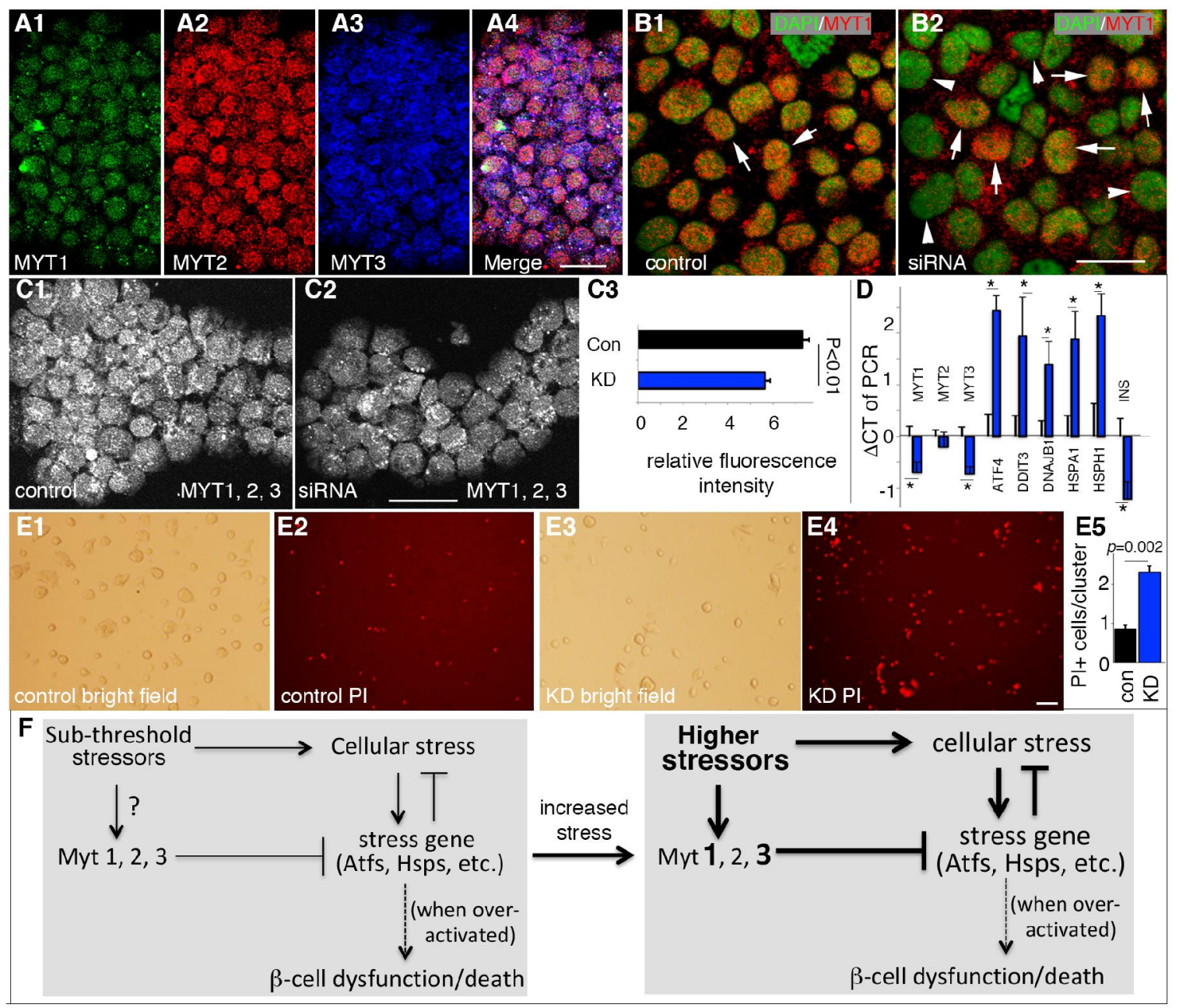




\section{Supplementary Tables}

Table S1: Summary of quantification data used in figures.

Table S2: List of genes differentially expressed between P1 control and 6F; Pdx1Cre Mip-eGFP ${ }^{+} \beta$ cells. Fold change (LogFC), p-value, adjusted p-value with Benjamini and Hochberg (BH) method, and gene expression levels in three controls and three mutants (reads per kilo-base per million reads, log2 transformed) were listed.

Table S3: Expression trajectory of several stress genes in human $\beta$ cells during T2D development.

Table S4: List of oligo nucleotides used for genotyping and PCR.

\section{Supplementary Figure Legends}

Figure S1: Quality control tests in Myt triple mutant mice. Related to Figure 1. Mice used here were derived from inter-cross of $M y t 1^{F /+} ; M y t 2^{F /+} ; M y t 3^{F /+} ; P d x 1^{C r e}$ mice or between $6 F$ and $M y t 1^{F /+} ; M y t 2^{F / F} ; M y t 3^{F / F} ; P d x 1^{C r e}$ or $M y t 1^{F / F} ; M y t 2^{F /+}$; $M y t 3^{F / F} ; P d x 1^{C r e}$ mice. The day of birth was counted as P1. For all quantification panels, the $p$-values [type 2, 2-tailed t-test except in G (ANOVA)] were marked on top of each assay. Error bars, SEM. "n" denotes the number of mice used.

(A) Myt TF deletion efficacy in $6 F$; $P d x 1^{C r e}$ islets, with a $6 F$ control presented (P14). Pdx1 signals (green) were used to identify the location of islets. Scale bars $=20 \mu \mathrm{m}$. 
(B) Myt TF detection in the hypothalamus regions of P14 $6 F$ and $6 F$; $P d x 1^{\text {Cre mice, }}$ labeled for each Myt TF and DAPI. Scale bars $=50 \mu \mathrm{m}$.

(C) The morphology of pancreatic exocrine tissues in P14 6F and 6F; Pdx $1^{\text {Cre }}$ mice. Islets were labeled with HRP signals (brown). All cells were visualized by Eosin counter staining (pink). Scale bars $=100 \mu \mathrm{m}$.

Figure S2: Myt TF mutant $\beta$ cells lacked notable cellular stress before phenotype development. Related to Figures 2 and 3. Mice used here were derived from crosses between $6 F$ and $M y t 1^{F /+} ; M y t 2^{F / F} ; M y t 3^{F / F} ; P d x 1^{C r e}$ or $M y t 1^{F / F}$; $M y t 2^{F /+} ; M y t 3^{F / F} ; P d x 1^{\text {Cre }}$ mice. The day of birth was counted as P1. For all quantification panels, the $p$-values (type 2, 2-tailed t-test) smaller than 0.05 were marked on top of corresponding assays. Error bars, SEM. "n", the number of independent islet preparations used, except that in $C$, where " $n$ " refers to the number of $\beta$ cells counted.

(A) Real-time RT-PCR assays of gene expression from P7 hand-picked islets.

(B) Pathways differentially expressed in P1 6F and 6F; Pdx1Cre $\beta$ cells, identified via Gene Set Enrichment Assays. Pathways with adjusted $p$ value $\leq 0.02$ were listed. (C) ER-width in P1 $\beta$ cells assayed via transmission electron microscopy. The presented quantification data were from double blind tests, counting the distance between two membranes of ER (distance between paired arrows). In the quantification, $\alpha$ cells were included as controls as well. 
(D) Radio-labeling $\left({ }^{35} \mathrm{~S}\right)$ and quantification of newly made proteins in $6 F$ and $6 F$;

$P d x 1^{\text {Cre }}$ islets within a four-hour window. The presented quantification data were from Image J-aided assays from exposed protein gels.

(E) Xbp1 mRNA spicing assays. Islets from 3-month old $d b / d b$ mice were used as positive control, showing increased $X b p 1$ splicing. The ratios between spliced (lower bands) and unspliced (upper bands) bands were presented (6F; Cre $\left.=6 F ; \mathrm{Pdx} 1^{\mathrm{Cre}}\right)$.

(F) Fox01 activation in $6 F ; P d x 1^{\text {Cre }} \beta$ cells. Pdx1 signals (green) were used to identify the $\beta$ cells. Note the presence of yellow nuclei (Fox01 activation) only in the $6 F$; $P d x 1^{\text {Cre }}$ sample at P14. Scale bars $=20 \mu \mathrm{m}$.

(G) Gene expression of several stress markers assayed via RNAseq, presented as Log2 (fragments per kb per million reads).

\section{Figure S3: Myt1 CHIP assay controls. Related to Figure 3.}

(A) Western blot to test the specificity of the Myt1 antibodies used in CHIP-PCR ("C", $6 F$ control islets. $\mathrm{M}, 6 F ; P d x 1^{\text {Cre }}$ mutant islets). An RNA polymerase II antibody was used as a positive loading/transfer control.

(B) Examples of fragmented chromatin from adult islet and acinar cells.

\section{Figure S4. The derivation and some characterization of Hsp-overexpressing}

islet cells. Related to Figure 4. For inducing OE, TetO ${ }^{3 H}$ and Rip $^{\text {rTTA }}$ mice were crossed. Dox was administered in the drinking water of pregnant females starting from E16.5 (16 th $^{\text {th }}$ day after the observation of vaginal plug). Dox application continued to the date of tissue collection. 
(A) The structure of $H s p-O E\left(\right.$ TetO $\left.^{3 H}\right)$ transgene. Note that two mRNA will be transcribed under the control of a bi-directional TetO promoter. Each mRNA will produce two proteins, with T2A peptide included between HspH1 and DnaJB1 or Hspa1b and eGFP.

(B) Level of Hspa1b OE in P2 Hsp-OE islets ( $p=0.01)$. Results were from four islet preps. Error bars, SEM.

(C) Restricted transgene expression, by virtue of monitoring eGFP expression, in $\beta$ cells of $H s p-O E$ islets (P4). Scale bars $=20 \mu \mathrm{m}$.

(D, E) Hsp-OE in 8-week old islets (E) or mice (F) in animals without prior exposure to Dox but treated with Dox for two days. Islets were isolated from mice and treated with $5 \mathrm{ng} / \mathrm{ml}$ Dox for two days. For in vivo activation, two-month old mice were intra-peritoneally injected with $10 \mu \mathrm{g}$ Dox.

(F-I) Production of several $\beta$ cell markers and Caspase 3 (Cas3) activation in P10 Hsp-OE islets. Scale bars $=20 \mu \mathrm{m}$. Single and merged channels were presented.

Figure S5. ATF4 overexpression (OE) in mouse $\beta$ cells. Related to Figure 5.

(A) The cross scheme used to activate ATF4 OE in $\beta$ cells.

(B) Level of ATF4 OE in P2 ATF4-OE islets. Results were from four islet preps. The Pvalues (type 2, 2-tailed t-test) were included in the panel. Error bars, SEM.

(C) Ad lib blood glucose in control and ATF4-OE mice at two stages, before and after weaning. The controls include wild-type, Ins1 ${ }^{C r e}$, and Rosa26-ATF4LoxTG mice, both males and females. The P-values (type 2, 2-tailed t-test) were included in the panel. Error bars, SEM. 
(D, E) An example of representative Cas3 activation in one-month old ATF4-OE islet. The few red dots in the ATF4OE panels are likely blood cells, which localize in the interstitial space between hormone-expressing cells. Scale bar $=20 \mu \mathrm{m}$.

(F) Insulin and Pdx1 production in P35 control and tdTomato (tdT)-expressing $\beta$ cells. tdT activation was achieved $\sim$ E16.5, using a $P d x 1^{\text {CreER}}$-based activation in an Ai9 Cre-reporter mouse line. Arrows point to the $\operatorname{td} \mathrm{T}+\beta$ cells. Compare the insulin (F1) and Pdx1(F3) signal intensities of tdT + and tdT- cells. Scale bar $=20 \mu \mathrm{m}$.

Figure S6. MYT expression in human islet/ß cells. Related to Figure 6.

(A) GSIS results of one batch of representative T2D islets $(p=0.26)$. Shown are insulin secretion within a 30-minute stimulation window.

$(\mathrm{B}, \mathrm{C}) \mathrm{MYT} 2$ and MYT3 in islet $\beta$ cells (identified by insulin production) treated with $17 \mathrm{mM}$ glucose for $\sim 40$ hours. Starting materials were functional human islets. (D, E) MYT1 and MYT2 in islet $\beta$ cells (identified by insulin production) treated with $0.6 \mathrm{mM}$ palmitate for $\sim 40$ hours. Starting materials were functional human islets. Scale bar $=20 \mu \mathrm{m}$, applicable to all images.

(F) RT-PCR assays in human islets treated with G17 or palmitate for $\sim 40$ hours. Whole islets were used for all assays. $P>0.05$ in all comparisons. 
Figure S1:

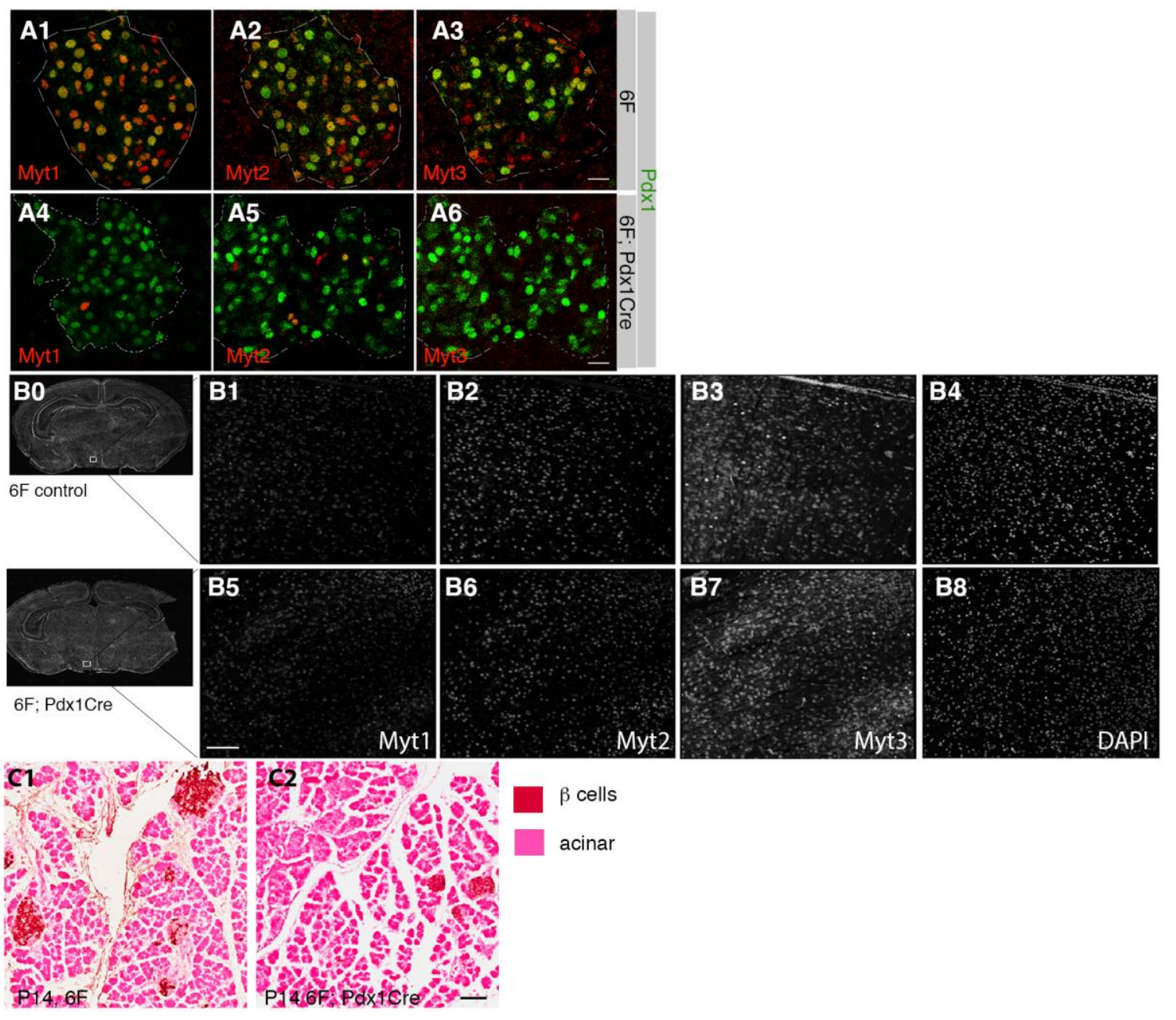


Figure S2;

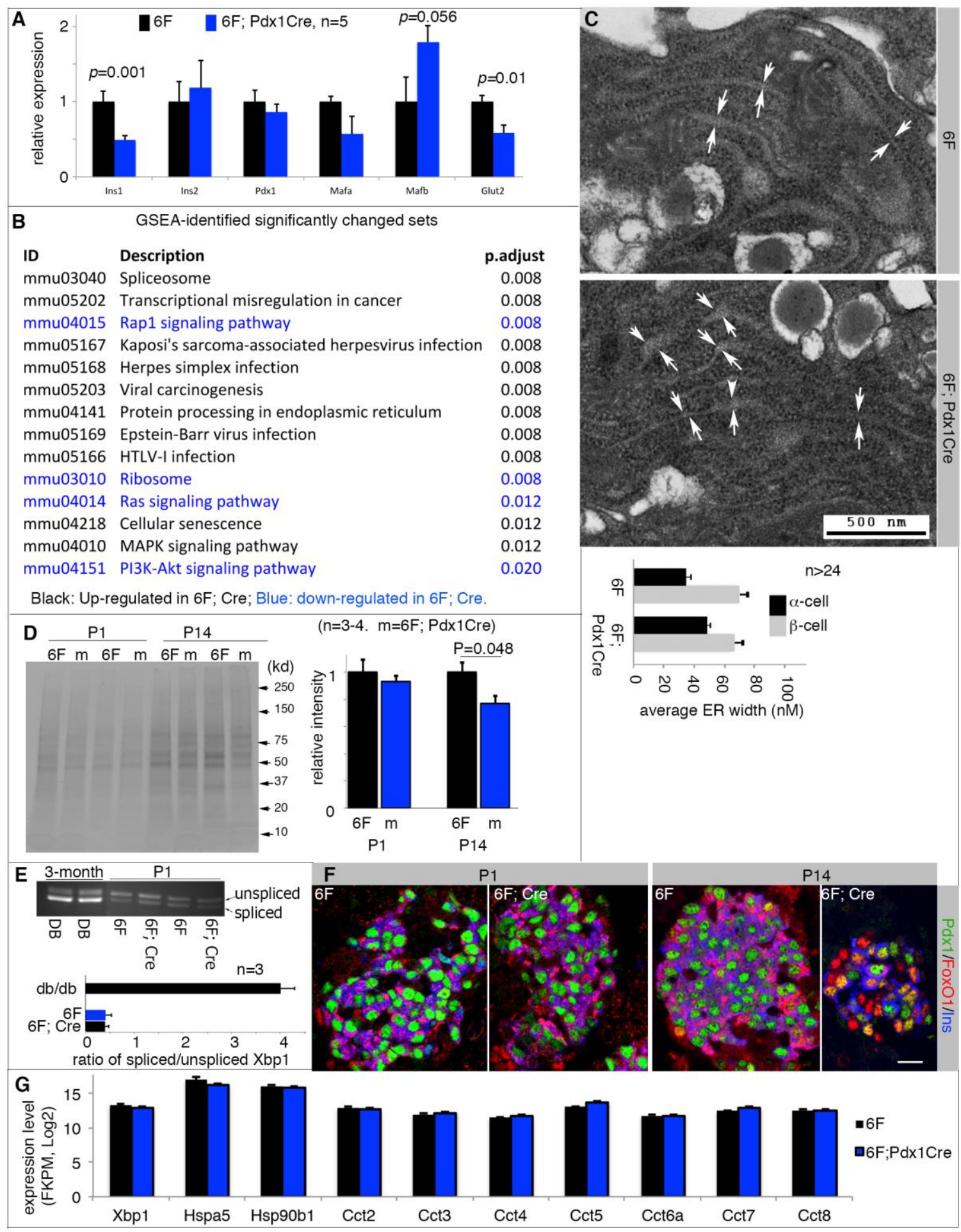




\section{Figure S3:}

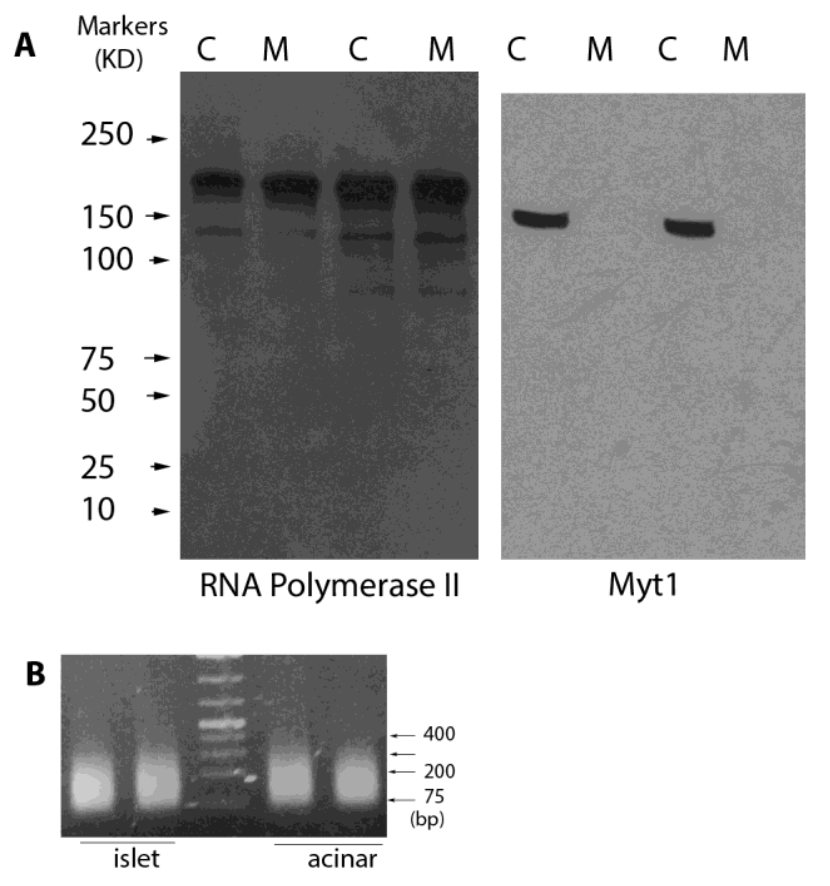


Figure S4:

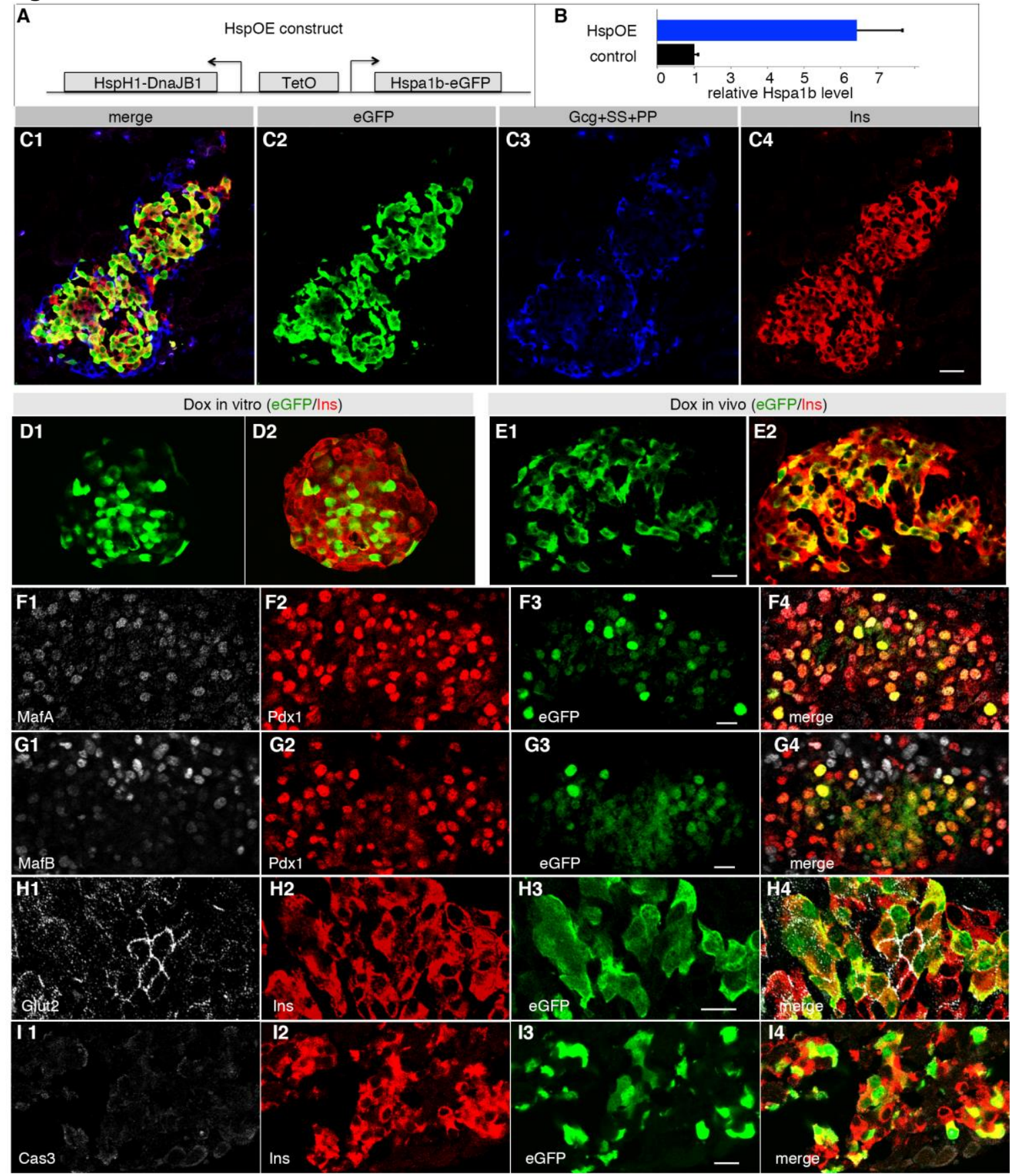




\section{Figure S5:}

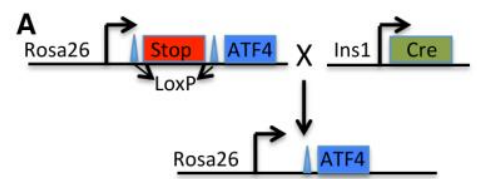

B ATF4 overexpression level

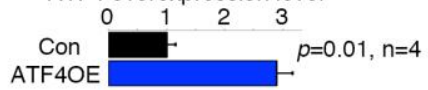

C

ad lib blood glucose (mg/dl)
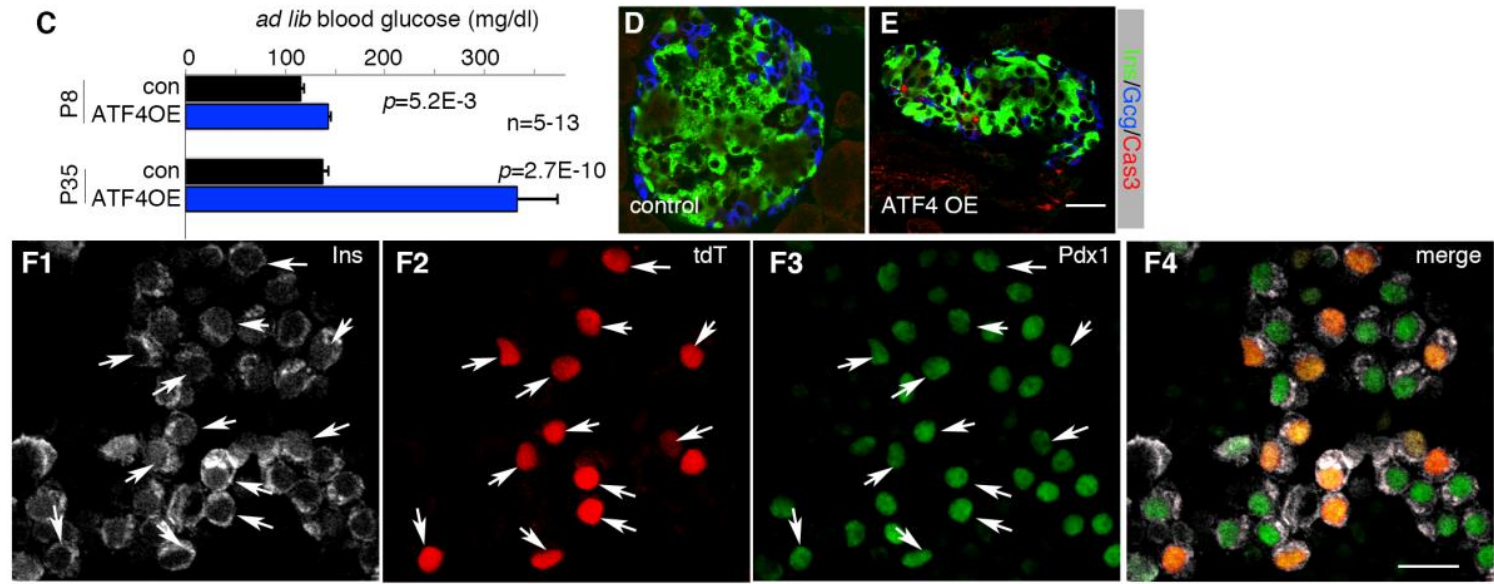
Figure S6:
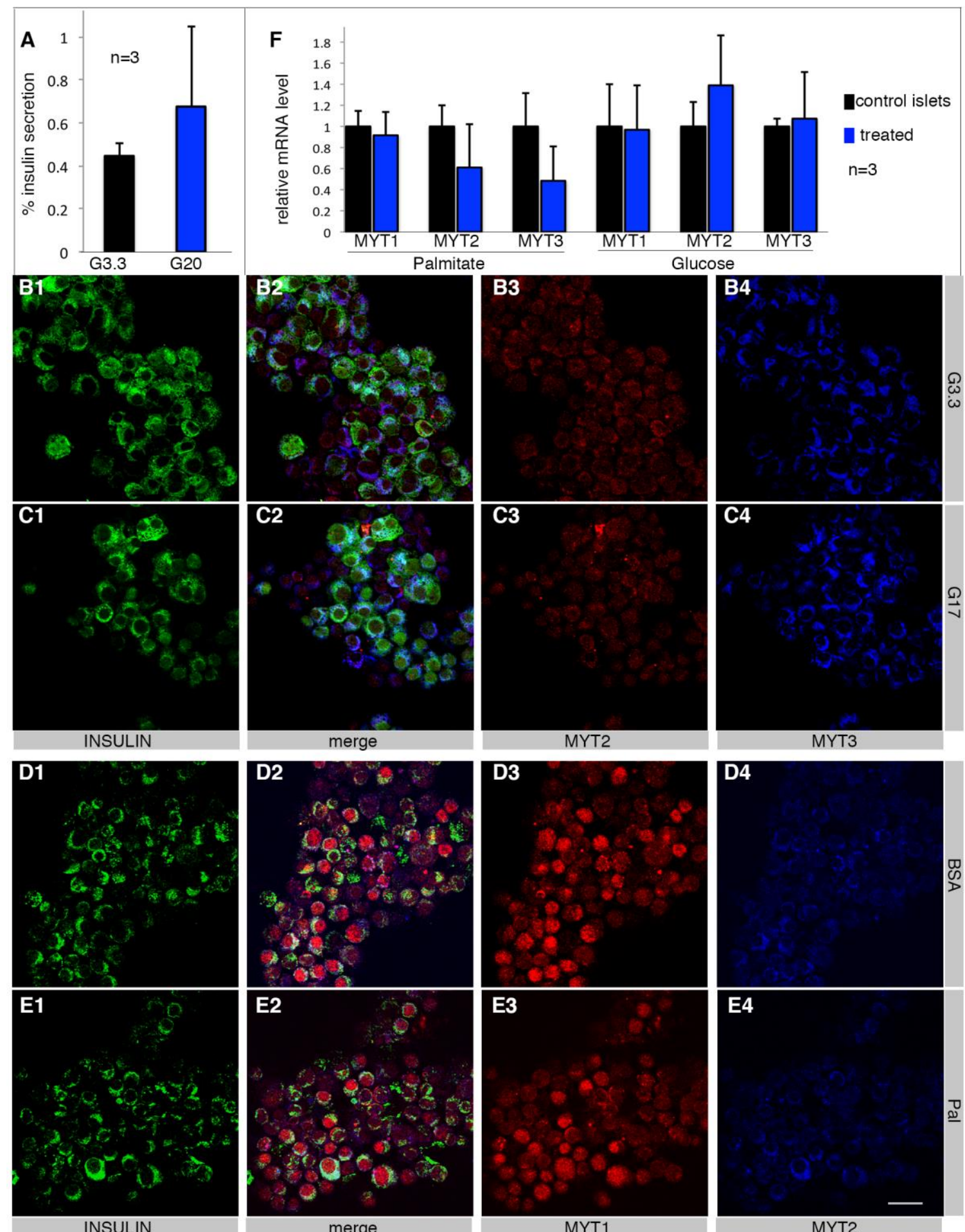

INSULIN

merge

MYT1 
Table S1 bioRxiv preprint doi: https://doi.org/10.1101/773846; this version posted September 18, 2019. The copyright holder for this preprint (which was not certified by peer review) is the author/funder. All rights reserved. No reuse allowed without permission.

Click here to access/download Supplemental Videos and Spreadsheets Table S1-Myt1-original \#.xlsx 
Table S2 bioRxiv preprint doi: https://doi.org/10.1101/773846; this version posted September 18, 2019. The copyright holder for this preprint (which was not certified by peer review) is the author/funder. All rights reserved. No reuse allowed without permission.

Click here to access/download Supplemental Videos and Spreadsheets Table S2-Myt1-genes.xlsm 
Table S3 bioRxiv preprint doi: https://doi.org/10.1101/773846; this version posted September 18, 2019. The copyright holder for this preprint (which was not certified by peer review) is the author/funder. All rights reserved. No reuse allowed without permission.

Click here to access/download Supplemental Videos and Spreadsheets Table S3-Myt1 RePACT.xIsx 
Table S4 bioRxiv preprint doi: https://doi.org/10.1101/773846; this version posted September 18, 2019. The copyright holder for this preprint (which was not certified by peer review) is the author/funder. All rights reserved. No reuse allowed without permission.

Click here to access/download Supplemental Videos and Spreadsheets Table S4-Myt1-oligos.xlsx 